\title{
El debate sobre política industrial
}

\section{Bernardo Kosacoff}

Experto Económico,

Oficina de la CEPAL

en Buenos Aires

\section{Adrián Ramos}

Consultor, Oficina de la

CEPAL en Buenos Aires

y Docente, Facultad de

Ciencias Económicas,

Universidad Nacional

de Buenos Aires
El presente artículo busca replantear el marco conceptual para pensar la política industrial en las condiciones que actualmente enfrenta la mayoría de los países más industrializados de la región; cabe agregar que en las economías de desarrollo industrial intermedio el debate tiene matices muy similares. En él se reseñan las teorías de la intervención gubernamental (sección II) y los argumentos de la política industrial (sección III). En seguida se considera la situación de los países en desarrollo, con una visión estructuralista (sección IV), y la interacción de los niveles macroeconómico y microeconómico (sección V). Luego se esboza el debate en el Banco Mundial (sección VI) y se expone el enfoque sistémico de la CEPAL (sección VII). En las reflexiones finales (sección VIII) se argumenta que toda nueva propuesta industrial debe evaluar los aprendizajes beneficiosos que se generaron en el pasado, así como los problemas asociados a los errores que se cometieron por el camino, y se plantea la necesidad de superar tales limitaciones e insuficiencias para tomar senderos que lleven a adquirir ventajas comparativas dinámicas. Un régimen de política industrial provee mecanismos de coordinación que faltan en una economía de mercados libres, y que pueden ser más eficientes en un contexto en que la interdependencia y la especificidad de los activos tengan importancia. La política industrial debe ayudar a la coordinación del cambio económico, a fomentar la experimentación y a preservar la diversidad. 


\section{I}

\section{Introducción}

Las nuevas condiciones de América Latina, particularmente en el marco de la estabilización y la apertura de las economías, son aceptadas como necesarias pero no suficientes para sustentar el desarrollo de largo plazo, que exige crecimiento y una nueva especialización. El reconocimiento de la existencia de mercados imperfectos y de la debilidad de las instituciones para inducir el desarrollo de ventajas comparativas dinámicas llevó a replantear las políticas industriales, que difícilmente encuentran respuestas en la reproducción de los instrumentos y el marco institucional de la etapa de sustitución de importaciones. El desafío es el mismo del pasado, pero las condiciones internacionales e internas tienen puntos de partida diferentes.

En el ámbito internacional se está viviendo una nueva fase de la internacionalización, caracterizada por mercados reales y financieros cada vez más globalizados. La intensificación de la competencia a nivel de países, sectores y empresas es uno de los rasgos centrales del entorno en el cual se desenvuelve la actual división internacional del trabajo. En la relación entre los nuevos patrones de comercio internacional y los modelos tecnoproductivos que caracterizan actualmente a los países más desarrollados influye la importancia cada vez mayor que están adquiriendo la calificación de los recursos humanos y la base científico-tecnológica como sustento de la formación de nuevas capacidades competitivas.

En el nuevo escenario internacional ganan importancia los procesos de conformación de bloques y nuevas formas de integración regional, que se articulan complementariamente con el escenario descrito. Unidos a la creciente apertura económica, van gestando un tránsito desde economías básicamente semicerradas a economías relativamente pequeñas y cada vez más abiertas, redefiniendo su participación en los procesos de integración y globalización.

Este difícil tránsito no empezó de la nada. Tuvo su punto de partida en senderos evolutivos en los que se fueron desarrollando capacidades tecnológicas. Las economías presentaban deficiencias a nivel microeconómico en términos de tamaño de plantas y escasa capacidad de especialización; asimismo, había fuertes desequilibrios macroeconómicos reflejados en la posición deficitaria del sector externo o en altos costos fiscales asociados al desarrollo de la industrialización. Pero, a pesar de todos estos problemas, junto con la producción de bienes industriales se fue generando una gran cantidad de capacidades tanto tecnológicas como de calificación de recursos humanos y de desarrollo empresarial e institucional. Es a partir de esa historia, con sus marchas y contramarchas, que cada país tiene por delante el desafío de pasar a las cadenas de mayor valor agregado, superando sus limitaciones y potenciando sus capacidades acumuladas.

El replanteo de la necesidad de desarrollar una estrategia competitiva que cuente con una articulada política industrial para fortalecer una nueva especialización tiene, en este sentido, un marco muy distinto al del pasado. Por lo tanto, la definición de una política industrial para economías en transformación relativamente pequeñas y con necesidad de restablecer el funcionamiento del sistema ecónomico, para lo cual los procesos de estabilización deben fundamentarse en cambios estructurales, será sin lugar a dudas muy distinta a la del modelo sustitutivo. De partida, esa política será mucho más compleja, pues deberá responder a requerimientos sectoriales, regionales y empresariales mucho más específicos y a la necesidad de aggiornamento de la ingeniería institucional ante los cambios internos e internacionales señalados. Uno de sus principales objetivos debería ser el de reducir la incertidumbre, para que los agentes económicos —en particular las PYME - puedan evaluar mejor los escenarios en que deben desplegar sus estrategias.

El presente trabajo se propone replantear el marco conceptual necesario para pensar la política industrial en las condiciones que actualmente enfrenta la mayoría de los países de la región. Sin embargo, los problemas que examinaremos no son exclusivos de ellos, y tanto en los países más industrializados como en las economías de desarrollo industrial intermedio el debate tiene matices muy similares. 


\section{II}

\section{Reseña de las teorías sobre la intervención gubernamental}

El papel del Estado en una economía de mercado ha sido uno de los temas más controvertidos de la teoría económica. En él se incluye la evaluación de los posibles beneficios de desarrollar políticas industriales. Chang (1994) reseña lo que se ha escrito sobre la intervención gubernamental, organizándolo en torno a cuatro elementos.

\section{Eficiencia}

Este concepto se examina en escritos sobre las fallas de mercado o la economía del bienestar. En ellos se analizan las fallas de los mecanismos de mercado en igualar los costos y los beneficios sociales y privados y se señalan políticas correctivas a través de la intervención estatal. Hay tres grupos de argumentos para justificar tal intervención.

i) Bienes públicos: La característica que los define es la "no exclusión"; es decir, una vez que un bien público es suministrado a alguien que pagó por él, también es accesible a los demás, ya que no resulta económicamente factible excluir a quienes no han pagado. Algunos autores señalan la "no rivalidad en el consumo", que se da cuando el consumo de uno no reduce el de los demás, pero que también puede darse aunque existan los medios para excluir a otros individuos (es el caso de los llamados "bienes club"). El problema de los bienes públicos es fundamentalmente de derechos de propiedad. Debido a las características señaladas hay siempre un incentivo para no demostrar las preferencias por este tipo de bienes; por lo tanto, es probable que su oferta sea menos que óptima. Entonces, el Estado debe intervenir, aplicando impuestos y proveyendo los bienes públicos con esos ingresos.

ii) Mercados no competitivos: La existencia de economías de escala y/o conductas colusivas puede desembocar en estructuras de mercado no competitivas. Cuando prevalecen monopolios u oligopolios en el mercado, la cantidad de bienes suministrados es menor que en un contexto competitivo. Entonces, el Estado debe intervenir para garantizar la producción óptima. También hay razones ajenas a la eficiencia para regular los monopolios; por ejemplo, la de que ellos conducen a la concentración del poder económico y político en manos privadas que no están sujetas a un control democrático. Algunas medidas que se aplican frente a esto son la legislación antimonopolios o la propiedad pública de las empresas.

iii) Externalidades: Estas existen cuando hay efectos de derrame desde la actividad de un individuo a las de otros, que provocan una discrepancia entre la estructura de costos y beneficios privados, por un lado, y sociales, por otro. En principio es posible resolver el problema definiendo en forma más precisa los derechos de propiedad y llevando a cabo negociaciones entre las partes. Sin embargo, en muchos casos esto es imposible debido a los altos costos de transacción que implica el proceso; entonces se justifica la intervención gubernamental para asegurar la provisión de bienes con externalidades, en cantidades socialmente óptimas.

\section{Moralidad}

El Estado como representante de los miembros de una sociedad puede intervenir en el mercado, si es necesario a costa de la eficiencia. El argumento moralista toma dos formas: i) el Estado puede intervenir en la provisión de bienes de mérito, que son aquellos cuya provisión la sociedad (a diferencia de las preferencias del consumidor individual) desea alentar o, en el caso de los bienes de demérito, quiere impedir; ii) la intervención gubernamental puede también estar justificada si la sociedad cree que las transacciones de mercado no son moralmente aceptables en algunas áreas (por ejemplo, donación de sangre y servicio de policía). Sobre la base del individualismo metodológico y su contraparte político-filosófica, el contractualismo, se señalaba que cualquier intervención gubernamental, salvo algunas funciones mínimas, es ilegítima debido a que viola la libertad individual como valor último de la sociedad humana. Por lo tanto, el liberalismo implica estar dispuesto a sacrificar la eficiencia económica en aras de la libertad individual cuando tal conflicto aparece.

\section{Intención}

La literatura sobre la economía política ha criticado el enfoque de las fallas de mercado debido a que asume que la intención o el objetivo del Estado es servir al 
bienestar general. Tres tipos de argumentos cuestionan este supuesto:

i) El Estado autónomo. El Estado puede actuar como una entidad con una función objetivo propia que es distinta a la de la sociedad en su conjunto.

ii) Los grupos de interés. El Estado se ve como un escenario dentro del cual grupos de interés económico o movimientos sociales normativos luchan o se unen para dar forma a las decisiones de política pública sobre las asignaciones de beneficios entre los grupos demandantes. Los grupos más poderosos serán más capaces de afectar las decisiones del Estado, por lo que las políticas económicas los favorecerán.

iii) Los burócratas que protegen sus intereses. Se ha postulado que los funcionarios públicos en modo alguno son diferentes de otros individuos que persiguen sus propios intereses. Debido a que los funcionarios obtienen beneficios de los salarios más altos que perciban y del mayor poder que tenga su propio departamento, es racional que intenten maximizar el presupuesto de sus oficinas, en vez de optimizar el producto social. Por lo tanto, los funcionarios públicos producirán bienes y servicios bajo provisión estatal en una cantidad mayor que la socialmente óptima.

\section{Habilidad}

El supuesto de un Estado omnipotente ha sido cuestionado en las publicaciones sobre las fallas de gobierno, utilizando dos argumentos: i) El argumento de la información, que señala que el Estado puede recolectar y procesar toda la información pertinente para corregir las fallas de mercado sólo a un costo que es mayor que los beneficios obtenidos. Tiene dos partes: i) una se refiere a información insuficiente y la otra a asimetría de información (problema del agente y el principal) dentro del Estado y entre el Estado y las entidades a las cuales se dirigen las políticas.

ii) El argumento de la captación de rentas, según el cual la intervención gubernamental genera derroches adicionales que pueden más que compensar los beneficios que produce; no sólo incurre en las tradicionales pérdidas por peso muerto, sino que también hace que algunos recursos se dirijan a actividades improductivas para captar las rentas generadas por la intervención. En las publicaciones sobre el tema se destaca que los resultados combinados de maximizaciones individuales pueden diferir profundamente según el marco institucional.

El debate sobre las fallas de gobierno ocupa un lugar central en lo que se ha escrito sobre la política industrial. Este elemento determinará en gran medida el resultado de las políticas que se adopten. En una revisión de los argumentos efectuada por Shapiro y Taylor (1990), se reconocen las dificultades existentes, pero a la vez se ponen de relieve los casos en que ha sido posible realizar intervenciones.

\section{III}

\section{Argumentos a favor y en contra de una política industrial}

En los años ochenta la intensificación de la competencia entre empresas pertenecientes a los países altamente industrializados que incursionaban en actividades consideradas de alta tecnología llevó a replantearse si convenían o no las intervenciones gubernamentales para inducir el patrón de industrialización. Por un lado, los proponentes de una política industrial señalaban que el desempeño de los sectores dinámicos de la economía dependía de las ventajas comparativas "creadas" por la ayuda gubernamental. Por otro lado, sus oponentes negaban tales argumentos, haciendo referencia a la "mano invisible" que haría que los recursos se asignaran a los usos que le fueran más deseables.
En un artículo publicado por la Organización de Cooperación y Desarrollo Económicos (OCDE), Grossman (1990) hace una adecuada síntesis de los argumentos conceptuales y de la información empírica que respaldan a una y otra de las posiciones contrapuestas sobre la promoción de nuevas actividades industriales. Elabora asimismo un marco para analizar las intervenciones gubernamentales a partir de la economía de bienestar, comparando los beneficios generados por una industria promocionada con los que podrían haberse creado si los recursos se hubieran asignado a otro sector de la economía. Distingue tres componentes del superávit generado por la industria: i) superávit del 
productor, que es el exceso del valor del producto de una industria sobre el costo de oportunidad de los recursos utilizados en la producción; ii) el superávit del consumidor, que es el exceso de la utilidad que deriva el consumidor de la compra de una cierta cantidad de un bien sobre el costo de tal adquisición, y iii) el superávit del gobierno, que es el exceso de ingresos que éste recoge desde la industria sobre los subsidios que paga. ${ }^{1}$

${ }^{1}$ El superávit de la industria es: $W=n[(p+z) x-S(x)]-n(f-v)+$ $[U(c)-p c]-\left(p-p^{*}\right) e-z n x-n v$, donde, $W$ : superávit total de la industria; $n$ : número de firmas en la industria; $x$ : nivel de producto de una firma local típica; $p$ : precio pagado por los consumidores locales; $z$ : subsidio por unidad de producto; $S(x)$ : costo social de oportunidad de los recursos utilizados para producir $x$, neto de costos fijos de entrada; $f$ : costo social de los recursos necesarios para entrar (se asumen iguales a los costos privados de entrada); $v$ : subsidio de suma fija para inducir la entrada; $c$ : nivel del consumo local; $U(c)$ : utilidad por consumir una cantidad $c$ del bien; $p^{*}$ : precio internacional del producto en moneda local; $e=n x-c$ : exportaciones netas (importaciones netas si es negativo). Los primeros dos términos miden el superávit del productor. El tercer término es el superávit del consumidor. Los últimos tres reflejan los costos de los subsidios a la exportación (o los ingresos de las tarifas a la importación, si $p$ es mayor que $p *$ y $e$ es negativo), o de los subsidios a la producción, y de los subsidios para inducir la entrada que ayudan a cubrir los costos fijos, respectivamente. La intervención gubernamental altera algunas de las magnitudes que se encuentran en el lado derecho de la ecuación. El cambio total en $W$ resulta de los cambios en las variables determinadas económicamente: $\Delta W=W \Delta x$ $+W_{n} \Delta n+W_{e} \Delta e+W_{p *} \Delta p *$. Los términos de esta ecuación pueden ser expresados como la suma de siete componentes distintos: 1) Efecto captura de beneficios: $n[p-m(x)] \Delta x$; donde $m(x)$ es el costo marginal privado. Proviene de mercados oligopólicos cuando las políticas inducen a las firmas a cambiar su nivel de producción. 2) Efecto externalidad: $n[m(x)-s(x)] \Delta x$; donde $s(x)$ es el costo marginal social. Aparece cuando las políticas inducen un cambio en el uso de los recursos en situaciones donde el monto que las firmas pagan por sus insumos es distinto al costo de oportunidad social. 3) Efecto beneficios por ingresar: $[p x-M(x)-f] \Delta n$; donde $M(x)$ es el costo privado total de producir $x$ unidades neto de los costos fijos de entrada $f$. Refleja el exceso de los beneficios operativos que obtienen las nuevas firmas inducidas por las políticas a ingresar sobre los costos privados de tal ingreso. 4) Efecto externalidad del ingreso: $[M(x)-S(x)] \Delta n$; cuando el número de firmas en la industria cambia, este término mide hasta qué punto los costos privados de la producción de las nuevas firmas exceden los costos sociales. 5) Efecto volumen de comercio: $(p-p *) \Delta e$; los precios internos serán distintos a su costo de oportunidad ( $\left.p^{*}\right)$ si existen políticas comerciales. Estas políticas que alteran el volumen de comercio tienen implicaciones para la eficiencia, debido a que las decisiones locales se basan en precios que difieren del costo de oportunidad. 6) Efecto términos de intercambio: $e \Delta p *$ : refleja los beneficios que obtiene un país cuando sus exportaciones comandan un precio mayor en el mercado mundial, o cuando es capaz de importar a precios menores. Las políticas que inducen una expansión de exportaciones provocan generalmente una caída en el precio mundial del bien, y por lo tanto son un componente negativo del superávit. Aquellas políticas que restringen las importaciones imparten un efecto positivo si el país es significativo en relación a los mercados mundiales y afecta el precio internacional del bien importado. 7) Efecto superávit del consumidor: $[u(c)-p] \Delta c$; donde $u(c)$ es la utilidad marginal del bien después de consumir $c$ unidades. Mide la ganancia social de una expansión del consumo del bien en cuestión.
El autor formaliza este planteamiento, identificando, por una parte, la base argumental del pensamiento más ortodoxo, que concluye con la crítica a toda forma de intervención para promover el desarrollo industrial. ${ }^{2}$ Por otra parte, como muestra el cuadro 1 , analiza los factores determinantes de algunas fallas de mercado (economías de escala, externalidades e imperfecciones en los mercados de capital y de bienes) y las distorsiones que ellas causan en un mercado que actúa bajo los supuestos de la competencia perfecta. De esta forma, establece el rango de las posibles intervenciones y sintetiza las principales referencias teóricas y empíricas que fundamentan la promoción de nuevas actividades industriales.

\section{Comparación con la organización de los mer- cados financieros}

Los argumentos planteados por Grossman, que justifican la intervención gubernamental selectiva tendiente a lograr un incremento del bienestar social, son complementarios y están claramente ilustrados, en el caso particular de los mercados financieros, en un reciente trabajo de Stiglitz (1993). Este mercado es particularmente significativo para el sector industrial.

Los mercados financieros, esencialmente, se vinculan con la asignación de recursos, por lo que se puede decir de ellos que constituyen el "cerebro" del sistema económico, el lugar central de la toma de de-

\footnotetext{
${ }^{2}$ El paradigma ortodoxo supone: ausencia de barreras a la entrada, firmas locales pequeñas que no pueden influir sobre el precio de mercado de sus productos, ausencia de externalidades, etc. Entonces, la libre entrada conduce a que los beneficios excedentes (aquellos que exceden los costos fijos necesarios para la entrada) sean cero. Los productores reciben $p+z$ por unidad de producto. Esto implica que $(p+z) x=M(x)+f$. Cada firma produce hasta que el costo marginal $m(x)$ iguala al precio $p+z$ que recibe. Los efectos se reducen a: 1) $-n z \Delta x$ y 3) $-z x \Delta n$. El primero es negativo si existe un subsidio a la producción $(z>0)$ para promover la expansión de las firmas. El segundo término también es negativo si se utiliza un subsidio a la producción para inducir la entrada $(\Delta n>0)$. Por los supuestos adoptados los efectos 2) y 4) desaparecen. También desaparece el efecto 7) puesto que cada consumidor selecciona un nivel óptimo de compras, igualando el precio de la última unidad comprada a su utilidad marginal, $u(c)=p$. Si se utiliza un subsidio para estimular las exportaciones $(\Delta e>0)$, el precio interno $p$ será mayor que $p^{*}$, y entonces el efecto 5) será negativo. Finalmente, si se utilizan subsidios a la exportación o producción, se expanden las ventas en los mercados mundiales, y por lo tanto cae el precio internacional $p *$ Si el país es exportador neto del bien en cuestión $(e>0)$, disminuye el bienestar nacional. Por lo tanto, para las industrias exportadoras, los subsidios a la producción o al comercio sólo generan componentes negativos en el análisis de los superávit. Es por ello que la promoción industrial por cualquier tipo de intervención sólo reduce el bienestar.
} 
CUADRO

Fallas de mercado: Factores, efectos y posibles intervenciones

(Argumentos sintetizados por Grossman)

\begin{tabular}{lll}
\hline $\begin{array}{l}\text { Factores determinantes de } \\
\text { algunas fallas de mercado }\end{array}$ & $\begin{array}{l}\text { Efectos distorsivos sobre el mercado de com- } \\
\text { petencia perfecta }\end{array}$ & $\begin{array}{l}\text { Posibles intervenciones estatales } \\
\text { sobre aspectos teóricos }\end{array}$ \\
& & y empíricos
\end{tabular}

\section{ECONOMIAS DE ESCALA}

A. Economías de escala "estáticas"

B. Aprendizaje por la práctica (dentro de la firma). Economías de escala "dinámicas".

C. Promoción de la entrada estratégica (Caso particular de economías de escala estáticas o dinámicas)
Grandes costos fijos de entrada. Pocas firmas capaces de entrar a escalas de producción que dejen beneficios.

Existencia de escala de operación mínima con costos medios decrecientes.

Existencia de curva de aprendizaje pronunciada. Los costos de producción son inicialmente elevados pero declinan rápidamente con la experiencia acumulada en la nueva actividad.

El tamaño del mercado mundial soporta sólo una firma en la actividad. El gobierno se compromete a apoyar a las firmas locales en su competencia con firmas extranjeras rivales por la posesión del mercado emergente.
Subsidio a la entrada si el excedente de los consumidores es mayor que las pérdidas operativas privadas y si el efecto es negativo por la caída de la ganancia de las firmas ya existentes.

Subsidio a la entrada durante la fase de aprendizaje si el excedente del consumidor es mayor que las pérdidas operativas privadas debido a esa entrada. El ingreso de más de una firma reduce el volumen de ventas de las existentes y la velocidad con la cual ganan experiencia y los beneficios del aprendizaje asociados a ésta.

Subsidio a la entrada debido a los beneficios monopólicos que obtiene la firma.

Horstmann y Markusen, 1986

Schlie, 1986

Alchian, 1963

Zimmerman, 1982

Lieberman, 1984

Bresnahan, 1986

Baldwin y Krugman,

1987a

Dasgupta y Stiglitz, 1988

Trajtenberg, 1989

Ethier, 1982

Brander y Spencer, 1985

Dixit y Kyle, 1985

Dixit, 1986

Dixit y Grossman, 1986

Grossman, 1986

Horstmann y Markusen,

1986

Baldwin y Krugman,

1987a y $1987 b$

Baldwin y Flam, 1989

Helpman y Krugman,

1989

\section{EXTERNALIDADES}

A. Investigación y desarrollo

Significativas inversiones en la creación de conocimiento. Características de "bien público" del conocimiento. Es eficiente y quizás inevitable que los frutos de los esfuerzos de investigación y desarrollo se expandan a través de la sociedad. Los agentes privados sólo se harán cargo de los costos si pueden internalizar los beneficios.
B. Aprendizaje por la práctica

(Fuera de la firma)
Las ganancias de productividad provenientes de la experiencia en la producción pueden acumularse en firmas que no son la que emprende el proceso de manufacturación (variante clásica del argumento de la industria naciente).
Subsidiar los costos privados de investigación y desarrollo.

Incitar a las firmas a internalizar las externalidades asociadas con la creación de nuevas tecnologías a través de la promoción de joint ventures para investigación y desarrollo. Incrementar la protección en el exterior de los derechos de propiedad intelectual. Utilizar subsidios a la producción o exportación, o protección del mercado interno, aunque generan simultáneamente efectos negativos.

Subsidio a la producción debido a los beneficios de la externalidad. La política comercial es una variable sustitutiva, que promueve el aprendizaje pero también induce simultáneamente efectos negativos.
Arrow, 1962

Griliches, 1979

Jaffee, 1984

Spence, 1984

Grossman y Shapiro, 1985

Griliches, 1986

Katz, 1986

Bernstein, 1988

Bernstein y Nadiri, 1988 y 1989

Chin y Grossman, 1989

Grossman y Helpman,

1989a y 1989 b

Lichtenberg y Siegel, 1989

Lieberman, 1982

Zimmerman, 1982

Bell, Ross Larson y

Westphal, 1984 
Cuadro 1 (continuación)

\begin{tabular}{|c|c|c|c|}
\hline $\begin{array}{l}\text { Factores determinantes de } \\
\text { algunas fallas de mercado }\end{array}$ & $\begin{array}{l}\text { Efectos distorsivos sobre el mercado } \\
\text { de competencia perfecta }\end{array}$ & Posibles intervenciones estatales & $\begin{array}{l}\text { Referencias bibliográficas } \\
\text { sobre aspectos teóricos } \\
\text { y empíricos }\end{array}$ \\
\hline $\begin{array}{l}\text { C. Inversión en capital } \\
\text { humano y capacitación } \\
\text { en el trabajo }\end{array}$ & $\begin{array}{l}\text { Externalidades en la inversión en capital hu- } \\
\text { mano. Las firmas intervienen en forma sub- } \\
\text { óptima. }\end{array}$ & $\begin{array}{l}\text { Subsidio a la inversión de capital humano. } \\
\text { Como en el caso de las externalidades en } \\
\text { investigación y desarrollo los subsidios a la } \\
\text { producción o las políticas comerciales no } \\
\text { garantizan solución al problema de } \\
\text { apropiabilidad. }\end{array}$ & $\begin{array}{l}\text { Horowitz y Sherman, } \\
1980 \\
\text { Maranto y Rogers, } 1984 \\
\text { Simpson, } 1984 \\
\text { Barron, Black y } \\
\text { Lowestein, } 1987\end{array}$ \\
\hline $\begin{array}{l}\text { D. Fallas de coordinación } \\
\text { y eslabonamientos }\end{array}$ & $\begin{array}{l}\text { Si las economías de escala son significativas } \\
\text { y la exportación está limitada por costos de }\end{array}$ & & $\begin{array}{l}\text { Scitovsky, } 1954 \\
\text { Pack y Westphal, } 1986\end{array}$ \\
\hline
\end{tabular}

y eslabonamientos verticales

y la exportación está limitada por costos de transporte o barreras comerciales, la entrada a la actividad de un productor puede estar inhibida por la inexistencia de comprador de su producto. Al mismo tiempo, un productor potencial que utiliza el producto anterior como insumo puede estar inhibido de entrar por la incapacidad de acceder a una oferta a bajo costo del componente. La solución de mercado involucra una falla de coordinación: ninguno de los dos se hace cargo de los grandes costos fijos, si bien ambos se beneficiarían si lo hicieran.

\section{IMPERFECCIONES EN EL MERCADO DE CAPITAL}

A. Divergencia de los costos social y privado de los fondos

B. Asimetrías de información

Existencia de una divergencia exógena entre el costo de oportunidad social de los fondos y la tasa a la cual el mercado los pone a disposición de los prestatarios. Tales divergencias pueden deberse a la incapacidad de evaluación de los prestamistas, a su aversión "irracional" al riesgo, o a su sobreestimación sistemática del riesgo de nuevas actividades.

Los prestatarios seguramente saben más sobre la naturaleza, riesgo, y probables retornos ante escenarios alternativos y sobre su propia capacidad para emprender una nueva actividad. Estas asimetrías no serían significativas para el prestamista si los contratos de deuda aseguraran el repago bajo todas las circunstancias. Pero los mercados de crédito se caracterizan por la protección del Estado bajo estatutos de responsabilidad limitada y por lo tanto, exponen al prestamista a la quiebra de la firma (problema de "selección adversa").

\section{IMPERFECCIONES EN EL MERCADO DE BIENES}

A. Reputación de calidad como barrera a la entrada
Imperfecta información sobre los atributos de los productos por parte de los consumidores. Problemas de falta de prestigio de calidad para los nuevos ingresantes.
Subsidio al crédito si las tasas privadas son inadecuadas.

Subsidio a los avales o compensación impositiva por las pérdidas de las firmas para aliviar parte de la exposición privada si la aversión al riesgo es demasiado grande. Tales subsidios y beneficios impositivos deben estar disponibles para todos los inversores en todos los sectores, a menos que se conozca que el mercado sistemáticamente discrimina contra cierto tipo de actividades.

Subsidios selectivos a la tasa de interés, sólo en el caso donde los mecanismos de mercado sistemáticamente seleccionan aquellas firmas o potenciales ingresantes que desde un punto de vista social son menos atractivos.
Kafka, 1962

Stiglitz y Weiss, 1981

De Meza y Webb, 1987

Flam y Staiger, 1989

Sen, 1989
Incentivos "diferenciales" para que las firmas produzcan bienes de alta calidad (por ejemplo, estándares de calidad mínimos)
Bagwell y Staiger, 1988 Grossman y Horn, 1988

Fuente: Elaboración propia basada en Grossman (1990).

a Estas referencias bibliográficas están tomadas de Grossman (1990), donde aparecen con mayores detalles. 
cisiones. Debido a este papel de los mercados financieros su desempeño es tan importante: si ellos fracasan en llevar a cabo su cometido adecuadamente, no solamente sus beneficios serán menores, sino que puede dañarse el funcionamiento de todo el sistema económico. Según Stiglitz, hay siete fallas de mercado que pueden justificar la intervención gubernamental en los mercados financieros: i) problemas de "bien público" en materia de supervisión financiera; ii) externalidades de la supervisión financiera, de la selección y de la concesión de préstamos; iii) externalidades de las turbulencias financieras; iv) mercados ausentes e incompletos; v) competencia imperfecta; vi) ineficiencia, en el sentido paretiano, de los mercados competitivos y vii) inversores desinformados.

El trabajo de Stiglitz señala también las formas de intervención gubernamental comúnmente observadas en los mercados financieros y un conjunto de principios que determinan las regulaciones en el sector. Para terminar, analiza una forma de intervención particular: la represión financiera. Stiglitz concluye que el Estado tiene un papel en los mercados financieros debido a las fallas de mercado descritas anteriormente.

\section{Costos de transacción y fallas de coordinación}

Otra forma de interpretar la política industrial nace del uso del concepto "costo de transacción" (véase Chang, 1994). La corriente que hace hincapié en los costos de transacción de la nueva economía institucional señala que las transacciones de mercado, a través de las cuales se hace la asignación de recursos en las economías de mercado, no son sin costo, como supone la economía neoclásica; puesto que los individuos poseen racionalidad limitada, destinan recursos a establecer salvaguardias contra las conductas oportunistas de la contraparte comercial (por ejemplo, a sufragar los costos de redactar y hacer cumplir un contrato). Este aporte teórico reciente subraya que el logro de la eficiencia (o la coordinación de las conductas de agentes interdependientes, pero a la vez independientes) conlleva costos que van más allá de aquellos que provienen de no lograr el mayor grado de bienestar social posible. Por lo tanto, desde este punto de vista, los costos incluyen no sólo los de producir bienes, sino también, en parte significativa, los de asignar los recursos entre las unidades de producción y de administrar el proceso de producción dentro de las unidades. Estos costos de coordinación entre las unidades económicas y dentro de ellas, que deben ser diferencia- dos de los costos ingenieriles puros, se han denominado costos de transacción.

Si los costos de transacción son aquellos en los que se incurre con el propósito de definir y redefinir los derechos de propiedad (y otros) de los agentes económicos, por un lado, y de redactar, revisar y hacer cumplir los contratos dentro de la estructura de derechos existente, por otro, los costos de la intervención gubernamental pueden ser también reinterpretados como costos de transacción. Los costos de información necesarios para tomar decisiones y aplicar políticas son de este tipo. Los costos derivados de actividades de captación de rentas que buscan redefinir la estructura de derechos de propiedad, también pueden ser clasificados de este modo. En el mundo real, tanto las intervenciones estatales como las transacciones de mercado generan costos. Por lo tanto, la comparación debe establecerse entre los costos de asignar los recursos a través de transacciones de mercado y los costos de hacerlo a través de intervenciones estatales. Surge así un nuevo papel del Estado: el de reducir los costos de transacción de la economía.

Una función relevante del Estado es establecer y hacer cumplir un sistema de derechos de propiedad bien definido que ahorre costos de transacción; si esto no se logra, aquellos agentes cuyas decisiones son interdependientes gastarán, de forma extraordinaria, recursos para resolver el problema de las externalidades. Aunque no necesariamente es una tarea estatal, el monopolio del uso legítimo de la violencia por parte del gobierno hace que el agente más eficiente para llevar a cabo esta función sea el propio Estado. Otro rol que desempeña el Estado en la reducción de costos de transacción es el de aminorar la inestabilidad macroeconómica. Ante una inestabilidad macroeconómica que aumenta, los agentes con racionalidad limitada destinarán recursos a actividades que buscan crear condiciones para hacer posible el cálculo racional (por ejemplo, redactar, revisar y hacer cumplir contratos de oferta de largo plazo y de subcontratación, o mantener inventarios). Como la inestabilidad macroeconómica es en esencia una falla de coordinación entre las actividades de distintos individuos, se puede extender el argumento al problema de la coordinación en general (por ejemplo, al establecimiento por parte del Estado de un sistema de pesos y medidas y de estándares tecnológicos).

Para lograr dicha coordinación el Estado no necesita suplantar completamente a las transacciones de mercado. Aun más, este ejercicio podría ser prohibitivamente caro, como lo demuestran las prácticas de 
planeamiento central en los países socialistas. Existen medios por los cuales el Estado puede reducir los costos de transacción sin eliminar todas las transacciones de mercado: i) cambiando la configuración institucional de la sociedad (puede dar respaldo legal para organizar a los agentes en grupos mayores y reducir el número de regateos necesarios, como hace el corporativismo social aplicado en Escandinavia o Austria); ii) a través de su influencia en el sistema educativo y en los medios de comunicación, promoviendo una "ideología" nacional, o sistema de valores, que ayude a reducir los costos involucrados en el intercambio de información y en las negociaciones (como sucede en la República de Corea y Japón, países considerados sociedades homogéneas); iii) proporcionando un "punto focal", o un consenso, alrededor del cual las decisiones pueden ser coordinadas (como sucede con las inversiones en proyectos complementarios en Francia y Japón).

Un régimen de política industrial ofrece mecanismos de coordinación que faltan en una economía de mercados libres. Como mecanismo de coordinación, la política industrial puede ser más eficiente en un contexto en el cual la interdependencia y la especificidad de los activos son importantes. En este caso, la coordinación a través del mercado incurriría en altos costos de negociación y la coordinación a través del planeamiento centralizado en altos costos de información, mientras que la política industrial probablemente tendría costos bajos de ambos tipos. La política industrial también emerge como una vía superior para promover el progreso técnico. Por un lado, no elimina el incentivo del beneficio, como lo hace el planeamiento centralizado, y a través de la socialización del riesgo puede promover transformaciones adicionales a las que el mercado puede inducir por sí solo.

Para examinar la lógica de la política industrial conviene separar el papel que desempeña en la dimensión estática y en la dinámica. En ambos casos la función de la política industrial es la misma: evitar fallas de coordinación. Como señala Chang (1994), cuando hay especificidad de los activos, la coordinación ex post a través del mercado puede ser antieconómica, pues las fallas de coordinación que involucran a los activos específicos generan una reducción neta en el monto de los recursos disponibles para la economía. Una de las características de las economías industriales modernas es el uso de tecnologías de producción que necesitan grandes inversiones fijas y, por lo tanto, tienen economías de escala. Además, una gran parte de sus activos son específicos o "hundidos". El resul- tado es una industria oligopolística, en la cual existe interdependencia estratégica en las decisiones de las firmas.

Bajo ciertas condiciones probables, esta interdependencia conduce a resultados ineficientes que justificarían la intervención estatal. En este caso, la intervención no sería necesariamente una política antimonopólica ya que los beneficios de quebrar el oligopolio pueden redundar en los mayores costos que resultan de escalas de producción subóptimas. Aquí la política industrial puede desempeñar un papel destacado, con medidas como las siguientes:

i) Coordinación de inversiones: puesto que la sobreinversión o la subinversión son problemas de incertidumbre estratégica que pueden hacer que varias firmas quiebren y se pierdan los recursos invertidos, el Estado puede intervenir en la industria para lograr que la entrada a ella sea la óptima, asegurándolo así a los potenciales ingresantes;

ii) Carteles de recesión: cuando la demanda cae temporalmente, es preferible organizar carteles de recesión a que las firmas comiencen una guerra de precios que puede conducir, entre otras cosas, a la pérdida de recursos sociales o a la sobrevivencia de las firmas más fuertes, las que luego extraerán beneficios monopólicos cuando se produzca la recuperación;

iii) Reducción negociada de la capacidad productiva: cuando una caída persistente de la demanda impone la necesidad de que algunas firmas salgan de la industria, es posible que ninguna quiera hacerlo, puesto que la salida de otras firmas la beneficiaría. Esto podría conducir a una guerra de agotamiento entre las empresas que no beneficiaría a ninguna, lo que justificaría la intervención.

Algunos oponentes de la política industrial señalan que aunque ésta puede resolver el problema estático de la coordinación, tal vez resulte muy perjudicial en el largo plazo, porque impide el funcionamiento de los mecanismos de selección natural de la economía $\mathrm{y}$, por lo tanto, el logro de la eficiencia dinámica, como lo demuestran los países con planeamiento central. Sin embargo, no indican que los cambios económicos también pueden requerir coordinación para ser exitosos. Además, si los riesgos han de ser asumidos sólo por los individuos, es posible que los cambios necesarios no se produzcan. La socialización del riesgo a través de la intervención estatal es una forma de promover transformaciones que involucran interdependencia.

La política industrial debe ayudar a la coordinación del cambio económico, a fomentar la experimentación y a preservar la diversidad. En un mundo de 
interdependencias, la existencia de una mejor alternativa no necesariamente implica el advenimiento de un cambio. En el mundo real muchos cambios involucran decisiones interdependientes. Asimismo, las industrias incipientes pueden necesitar ciertas garantías (por ejemplo, en cuanto a la entrada de potenciales competidores) para lanzarse a un sendero con amplia creación de conocimiento. Puede ser conveniente proteger a estas industrias y coordinar los proyectos que compitan entre sí. Cuando el mercado en cuestión ha madurado sólo queda hacer política industrial estática por las líneas de los "carteles de recesión". Cuando el mercado es senil, el papel de la política industrial resurge en la coordinación de salidas negociadas y de destrucción de la capacidad instalada. En una relación entre política industrial y ciclo de producto se ve que la política industrial dinámica sólo está presente en la primera de estas etapas.

Por último, como argumenta Nelson (1989), es preferible despilfarrar en la duplicación de esfuerzos innovativos que avanzar en una sola dirección, que puede resultar equivocada. La diversidad tiene sus ventajas, dado que no se conoce con certeza el futuro. El lugar de la política industrial en la innovación tecnológica está en la complementación de un mercado de capitales imperfecto, en el subsidio al ingreso de firmas a actividades con altos costos fijos de entrada y en la coordinación de la investigación universitaria y su articulación con el mundo de la producción. Para Chang, el crecimiento se explica porque los agentes han experimentado con nuevas cosas y con formas nuevas de llevarlas a cabo. Para que esto fuera posible aparecieron muchas instituciones que permitieron socializar los riesgos inherentes a la actividad innovativa. El Estado puede proveer otras.

\section{Construir el mercado}

En el intento de construir un marco conceptual para un nuevo enfoque de la política industrial en una economía abierta, Bianchi (1993 y 1994) ha elaborado un conjunto de elementos de suma utilidad. Ha rescatado la idea de mercado de Adam Smith, que fue desarrollada para las sociedades capitalistas emergentes y que se contrapone con las características de "lealtad y protección" de los mecanismos feudales, rígidamente basados en intercambios jerárquicos determinados por la posición social de los actores. El mercado para Smith es una institución social compleja y un nexo de relaciones horizontales, en el cual el poder relativo no está dado, sino que es alcanzable sobre la base de la habi- lidad para organizar la actividad productiva. Este mercado requiere reglas colectivas y una autoridad en condiciones de tutelar y estimular la competencia entre los agentes económicos, fundamento de los cambios estructurales. La eficiencia de la producción depende de la capacidad para organizarla de modo que desarrolle conocimientos específicos y se potencie en la retroalimentación de especialización y complementariedad. En el esquema smithiano la interacción social no es sólo competitiva, sino también cooperativa, ya que la división del trabajo se basa en las especializaciones complementarias de varios individuos y varias firmas. Es evidente que la dinámica social recibe un impulso mayor cuando existe multiplicidad, es decir, cuando hay un gran número y variedad de sujetos interactuando en la economía.

La intervención gubernamental se justifica en función de aumentar la división del trabajo, ampliar el mercado y facilitar el uso de todo el poder del mercado para el desarrollo de la competitividad. Esta intervención no es suficiente a nivel individual; tendrá mejores efectos si surgen coaliciones progresistas con miras a generar reacciones hacia la innovación, que tiendan a hacer coincidir los beneficios individuales y sociales. Smith recuerda que una economía basada en el desarrollo de las fuerzas de mercado requiere un Estado fuerte para garantizar los derechos de propiedad y para legitimar los contratos privados, pero también para asegurar aquellas externalidades positivas que ningún ciudadano individual podría sustentar por sí mismo, como la defensa, la justicia, y las actividades públicas necesarias para el crecimiento colectivo (entre otras, las comunicaciones y los sistemas educativos y de salud).

Smith estaba contra todo tipo de proteccionismo y fue un defensor del libre comercio, que para él significaba una ampliación del mercado y, por lo tanto, un incremento de la multiplicidad de los sujetos competidores. En particular, cuando el subdesarrollo económico se une al deterioro institucional, lo que se necesita no es "retornar al mercado" sino "construir el mercado". Esto significa actuar sobre las instituciones de la vida colectiva y proveer las capacidades que permitan a la mayoría de los sujetos tomar parte en ella de manera efectiva. Asimismo, las políticas públicas para el desarrollo industrial deben estar orientadas no sólo a favorecer un cambio en el entorno institucional en el cual las firmas realizan sus operaciones, sino también hacia acciones concretas que favorezcan la cooperación industrial entre las firmas para permitir la especialización individual en un contexto de complementariedad y ampliación del mercado. 
De haber un cambio en la situación — por ejemplo, frente a las perturbaciones que traigan consigo los procesos de apertura comercial- es preciso identificar las políticas necesarias para acelerar cambios estructurales e institucionales, con miras a establecer las nuevas condiciones y derechos de participación - con igualdad de oportunidades- de los agentes económicos y potenciar sus capacidades con el fin de facilitar una integración activa y creciente en la globalización. Para ello es necesario construir un sistema de interrelaciones con consenso, en el cual las condiciones sistémicas sean el eje articulador de políticas macroeconómicas retroalimentadas con la "construcción de capacidades en lo cotidiano". Esto significa establecer o reforzar redes, potenciando los vínculos entre las instituciones y las firmas, y las relaciones espaciales - a nivel local, regional, nacional e internacional-.

Una situación de autarquía es siempre difícil, ya que existe el peligro de una insatisfacción interna creciente y del surgimiento de coaliciones regresivas que bloqueen el cambio. En este contexto, un movimiento proteccionista puede ser un resultado regresivo, o una solución intermedia para permitir la reorganización interna que podría transformar las coaliciones potencialmente regresivas en coaliciones capaces de identificar vías de desarrollo colectivo a través de la redefinición de la división del trabajo. Un acuerdo de integración económica en un nivel regional puede, por lo tanto, ser un instrumento para guiar el proceso de apertura y el proceso de ajuste estructural de modo de sustentarlos sin provocar los daños de una acción demasiado rápida ni caer en situaciones de proteccionismo indefinido. Es posible generar efectos dinámicos si el pasaje hacia la unión aduanera se regula en el tiempo, para permitir el ajuste de las estructuras productivas nacionales durante la transición; se forma así una coalición progresiva que empuja hacia la apertura completa, incrementando el número de aquéllos capaces de sostenerla a través de un proceso de ajuste estructural rápido.

\section{IV}

\section{El caso de los países en desarrollo: una visión estructuralista}

Son muchos los autores que indagan en las causas de los desempeños muy desiguales de los países semiindustrializados en su intento de garantizar un proceso autosostenido de crecimiento económico y mejora del bienestar social. Entre ellos, Lall (1992 a y b; 1993; 1994 a y b) centra su atención en el debate sobre la política industrial y su vinculación con el concepto de capacidades tecnológicas para explicar los distintos desarrollos industriales y tecnológicos .

La necesidad de una política industrial descansa en la eficiencia de los mercados. Si los mercados trabajan perfectamente, alcanzarán resultados óptimos que por definición no podrían ser mejorados por algún tipo de intervención. Allí donde los mercados no trabajan perfectamente en este sentido, podría existir la necesidad de intervenciones para mejorar el desempeño económico. Esto va a depender de la naturaleza y extensión de las fallas de mercado y de la capacidad de los gobiernos para diseñar y llevar a cabo las intervenciones necesarias (evaluando, asimismo, los costos potenciales de las fallas del gobierno). Lall plantea tres vi- siones alternativas sobre el papel de la política industrial: la visión neoclásica, la visión facilitadora del funcionamiento del mercado (market-friendly) y la visión estructuralista. Las diferencias entre ellas se basan en los supuestos que cada una hace sobre cómo funcionan los mercados en los países en desarrollo y sobre cuán capaces son los gobiernos de superar las fallas de mercado (donde éstas existan).

Según la visión neoclásica, todos los mercados son perfectos y cualquier intervención distorsiona la asignación de recursos; la optimización estática de la asignación de recursos que se obtiene a partir de mercados libres conduce también a la maximización del crecimiento.

Según la visión facilitadora del funcionamiento del mercado, los países en desarrollo sufren de fallas de mercado. Por lo tanto, se necesitan intervenciones funcionales y selectivas para superarlas; pero en la práctica sólo las primeras son factibles y deseables, ya sea porque aquellas fallas que requieren remedios selectivos son insignificantes para el desarrollo indus- 
trial o porque las intervenciones selectivas son inherentemente más costosas que las fallas a las que se dirigen (las fallas del gobierno son siempre mayores que las fallas de mercado en esta clase de situaciones). Esta visión abandona algunos de los supuestos de la postura neoclásica. Acepta que los mercados de factores pueden no operar perfectamente, y que los mercados de la educación, en particular, pueden necesitar intervenciones para crear la base de capital humano que requiere la industrialización, las que deben ser favorecedoras del mercado (es decir, no selectivas) por el supuesto implícito de que las habilidades son genéricas. Reconoce que puede haber fallas de mercado en la coordinación de las decisiones de inversión dentro de la industria, las que se deben a varias razones: ausencia de mercados de información, deficiencias del mercado de capitales, economías de escala, inversiones interdependientes en actividades verticalmente relacionadas, externalidades en la creación y aprendizaje de habilidades y eslabonamientos múltiples.

La visión estructuralista señala que tanto las intervenciones funcionales como las selectivas son necesarias para promover el desarrollo, y que los gobiernos son capaces de efectuarlas. En ausencia de intervenciones selectivas, la industrialización puede tener lugar, pero verá afectados su patrón y profundidad, y en los países en desarrollo tenderá a ser frágil en la mayoría de las circunstancias. Debido a que las fallas de mercado difieren en su incidencia e intensidad a través de diferentes actividades, las intervenciones para corregirlas necesariamente deben ser selectivas. Sin ellas, predice la teoría, la asignación de recursos sería subóptima y el crecimiento se restringiría. La distinción entre intervenciones favorecedoras del mercado y selectivas es un falso dilema. No existe base económica para distinguir entre intervenciones funcionales y selectivas: cualquier intervención que corrige una falla de mercado favorece a éste. Tampoco la economía da alguna razón a priori para argumentar que más allá de las intervenciones funcionales el gobierno probablemente hará más daño que bien. Este es un argumento político de dudoso valor empírico.

Sobre la base de esta visión estructuralista, Lall desarrolla una serie de argumentos que se focalizan en la adquisición de capacidades tecnológicas y en las fallas que se enfrentan en este proceso. Indica que en la manufactura dichas capacidades no se reducen a la tecnología incorporada en el equipo físico o en manuales, planos y patentes adquiridos por la firma, si bien éstos constituyen los instrumentos con los cuales las capacidades son puestas a trabajar. Ni son únicamente las calificaciones educativas que poseen los empleados, si bien una base receptiva a la adquisición de capacidades depende en gran medida de la educación y capacitación del personal involucrado. No lo son tampoco, aisladamente, las habilidades y el aprendizaje por el que pasan los individuos en la empresa, si bien representan los ladrillos con que se construyen capacidades a nivel micro. Las capacidades son la forma en la cual una institución — por ejemplo, una empresa - combina todo lo anterior para funcionar como una organización, con interacción constante entre sus miembros, flujos efectivos de información y decisiones, y una sinergia mayor que la suma de las habilidades y conocimientos individuales. Es conceptualmente útil considerar el desarrollo de la competitividad a nivel de la firma como inversión en tecnología incorporada acompañada por inversiones en habilidades, información, mejoras organizacionales y relaciones con otras firmas e instituciones.

La exposición a los mercados internacionales ofrece varios estímulos al desarrollo de capacidades. La competencia internacional estimula los esfuerzos por reducir costos, mejorar la calidad, e introducir nuevos productos; permite obtener economías de escala, y provee información constante sobre las mejoras del diseño y los procesos que dinamizan las tasas de incremento de la productividad (ganancias en eficiencia técnica dinámica). Sin embargo, para alcanzar los niveles internacionales de eficiencia en tecnologías complejas — con difusión de externalidades y retroalimentación de actividades estratégicas - se requiere de tiempo, inversiones y esfuerzos. Para las empresas sería muy difícil correr con los costos involucrados si están expuestas a la competencia global desde el comienzo $\mathrm{y}$, por su parte, los mercados de capitales generalmente no están preparados para respaldarlas. Por lo tanto, hay argumentos vinculados al tratamiento de la industria incipiente que son válidos para la protección de las nuevas industrias, pero no en el sentido usual de protección baja y uniforme. La duración y alcance de la protección no pueden ser uniformes cuando las diferentes tecnologías tienen distintos costos y períodos de aprendizaje.

No todas las fallas de mercado requieren intervenciones. La necesidad de intervenir surge cuando las soluciones no aparecen o necesitan estímulos para aparecer. El riesgo de la falla del gobierno debe ser enfrentado siempre que se recomienden soluciones políticas para las deficiencias del mercado. El gobierno, como el mercado, pueden tener grados de éxito y de fracaso, y, al igual que el mercado, los gobiernos 
pueden mejorar con tiempo y esfuerzo. En algunas tareas, tal vez no haya alternativa a la intervención del Estado. En otras, es necesario realizar un balance razonable entre los costos y beneficios de esa intervención, por un lado, y las fallas del mercado, por otro. Está ampliamente aceptado que la provisión de educación básica y de servicios de infraestructura vinculados al desarrollo industrial y tecnológico debe estar en manos del gobierno. En esa dirección, aparece como ineludible la necesidad de fortalecer sus capacidades y mejorar su desempeño. El problema más serio se plantea cuando las formas de intervención son más selectivas. Estas políticas requieren enormes habilidades, información y disciplina de parte del gobierno, pues suelen propiciar conductas de captación de rentas y el surgimiento de grupos de presión. Podrían ser muy costosas si se las formula o aplica mal, pero si se llevan a cabo correctamente determinarán la naturaleza y el éxito del desarrollo industrial.

Hay varias fallas de mercado que enfrentan las empresas de los países en desarrollo. La naturaleza de estas fallas no es general. Ellas dependen de los objetivos específicos de cada país en lo que toca a las actividades a las cuales quiere ingresar, el grado de ampliación de la integración local que busca, y el nivel de competencia tecnológica y capacidades innovativas endógenas que desea desarrollar. Las necesidades de intervención deben ser calculadas en este marco. El desarrollo industrial no significa sólo comenzar nuevas actividades. A medida que las economías progresan y maduran, significa profundizar el proceso en alguna o todas de estas cuatro maneras: introduciendo mejoras tecnológicas en los productos y procesos dentro de las industrias, ingresando en nuevas actividades más complejas y exigentes, incrementando el contenido local, y dominando tareas tecnológicas más complejas dentro de las industrias (desde las de ensamblaje hasta aquellas necesarias para actividades de mayor valor agregado, adaptación, mejoramiento y finalmente diseño, desarrollo e innovación). Cada una tiene sus propios costos de aprendizaje. El profundizamiento progresivo es hasta cierto punto una parte natural del desarrollo industrial, pero no es inevitable. Su patrón e incidencia difieren ampliamente, dependiendo de las estrategias seguidas por las sociedades.

El proceso de formación de capacidades puede enfrentar varias fallas de mercado. En cuanto a productos, los mercados libres pueden no dar las señales correctas para la asignación de recursos, y en cuanto a factores, pueden no conducir a una oferta óptima de insumos, particularmente habilidades e información.
Los mercados libres pueden adolecer de dos tipos distintos de fallas: i) las que afectan la asignación óptima de las inversiones entre las actividades simples y las complejas, y ii) las que afectan esa asignación entre las inversiones físicas, la compra de tecnología y los esfuerzos tecnológicos internos. Las primeras son el sustento del caso clásico de la protección a la industria incipiente. En presencia de costos de aprendizaje, un ingresante tardío a una industria necesariamente enfrenta mayores desventajas que aquellos que emprendieron antes el proceso de aprendizaje. Dadas la incertidumbre, la escasez de información y las imperfecciones del mercado de capitales que son endémicas en los países en desarrollo, la exposición completa a la competencia importadora puede inhibir la entrada a actividades con tecnologías relativamente más complejas. Debido a que los costos de aprendizaje difieren de una actividad a otra, las intervenciones para asegurar la asignación eficiente de los recursos deben ser selectivas en lugar de uniformes.

Las segundas, que afectan la profundización de las capacidades dentro de las actividades industriales, pueden también sufrir de fallas de mercado. Arrow (1962) señaló hace mucho tiempo que el mercado libre puede fallar en asegurar la actividad innovativa óptima debido a la imperfecta apropiabilidad de la información y de las habilidades. Los países en desarrollo enfrentan además otro problema. Generalmente es fácil importar "paquetes" tecnológicos del exterior, donde el proceso está comercialmente probado: el proveedor entrega el equipo y los programas, los pone en funcionamiento, realiza la capacitación y las adaptaciones, y administra la operación y la comercialización. En su forma extrema, este procedimiento adquiere la forma de inversión extranjera directa (IED). Aunque constituye una manera efectiva y relativamente menos riesgosa de acceder a la tecnología, no conduce a que los países en desarrollo adquieran más capacidades, fuera de las habilidades necesarias para producir. El paso desde las actividades de producción a las innovativas involucra una decisión estratégica diferente, que los inversores extranjeros en dichos países están poco dispuestos a adoptar. Por lo tanto, existe el riesgo de fallas de mercado en la profundización de las capacidades debido a los costos de aprendizaje, que son muy similares en naturaleza a los que se dan en el caso de la industria incipiente. Para asegurar la asignación social óptima, puede ser necesario restringir selectivamente la importación de "paquetes" tecnológicos y promover la de tecnologías "externalizadas" (licencias o equipamiento). Muchas tecnologías, sin embargo, sólo 
están disponibles a través de la IED, o son demasiado complejas para las capacidades locales; éstas deberán importarse en paquetes. Puede ser necesario también promover el surgimiento de firmas de mayor tamaño. La profundización tecnológica puede ser un legítimo objetivo de la política industrial, ya que el desarrollo de capacidades endógenas de diseño e innovación tiene varias externalidades positivas.

Estas consideraciones también se aplican a la profundización de la integración local mediante el desarrollo de proveedores locales y subcontratistas. Además de traer beneficios productivos, las interrelaciones consecuentes aceleran la difusión de tecnologías, acrecientan la especialización y aumentan la flexibilidad industrial. En particular, el surgimiento de proveedores locales de equipos puede elevar la generación y difusión de tecnologías. Debido a estas externalidades, podría justificarse la promoción de conjuntos de actividades relacionadas, las que de otro modo no serían capaces de coordinar sus inversiones, y también la selección de aquellos conjuntos de actividades con mayor potencial de aprendizaje, por involucrar tecnologías avanzadas. Una vez más, la naturaleza de las fallas de mercado dependería de la economía considerada y de sus ambiciones tecnológicas.

Puesto que las necesidades de habilidades e información difieren en las distintas actividades industriales, las intervenciones en estos mercados de factores deben estar integradas con las que promueven las actividades mismas o la profundización tecnológica. Las intervenciones que facilitan el funcionamiento del mercado son, por lo tanto, necesariamente selectivas, toda vez que las habilidades y la información devienen específicas en lugar de genéricas. Finalmente, como la protección reduce el aliciente a invertir en desarrollar capacidades, la política industrial debe ofrecer incentivos compensadores en la forma de requisitos de desempeño (entrada a mercados de exportación en un plazo corto).

El desarrollo de la competitividad industrial y su evolución dinámica en el tiempo exigen que las firmas inviertan continuamente en el aprendizaje de nuevas capacidades y en el mejoramiento de éstas. El proceso de aprendizaje enfrenta varias fallas de mercado que la teoría convencional desestima. Una vez que se las tiene en cuenta, el alcance de la política industrial para crear y sostener ventajas comparativas surge más claramente. En la mayoría de los países en desarrollo el problema no es la construcción de nuevas industrias, puesto que tienen significativas estructuras industriales, sino el que éstas sean ineficientes. Tales países han invertido relativamente poco en la formación de capacidades industriales, o han desarrollado un tipo incorrecto de capacidades (dirigidas a producir con los materiales disponibles o a adaptar productos para mercados internos protegidos, antes que a reducir costos, elevar la calidad e introducir constantemente nuevos productos). Por lo tanto, necesitan reestructurar las industrias existentes y reasignar recursos con eficiencia. Esto involucra la liberalización de los regímenes de comercio y competencia, la desaparición de actividades que no puedan ser competitivas dentro de un lapso razonable con un aceptable nivel de inversión en reestructuración, y el progreso de actividades que podrían ser eficientes si se mejoraran sus capacidades tecnológicas y administrativas y se renovara su equipamiento. Un cuidadoso programa de liberalización en etapas, unido a un conjunto coherente de medidas de apoyo en los frentes de tecnología y habilidades, podría permitir que ciertas actividades alcanzaran estándares internacionales.

En síntesis, la promoción del desarrollo industrial puede necesitar intervenciones para superar fallas de mercado en la asignación de recursos entre actividades y dentro de las firmas. Estas intervenciones deben ser selectivas y encajar en el proceso de aprendizaje de las firmas. Pueden cubrir determinadas actividades o conjuntos de actividades, y pueden requerir la promoción del surgimiento de empresas de mayor tamaño. Deben estar integradas con las intervenciones selectivas en los mercados de factores, incluidas las medidas que afectan el modo de importar tecnología. Y deben ser compensadas por estímulos a invertir en la formación de capacidades.

El esquema que se muestra en el cuadro 2 fue desarrollado por Lall (1993) para analizar los factores determinantes del desarrollo industrial y tecnológico, las fallas de mercado existentes y las posibles políticas correctivas. El largo proceso de desarrollo de capacidades se enfrenta con un importante conjunto de fallas de mercado que sugieren formas muy variadas de intervención. La experiencia indica que las diferencias de desempeño entre los países están asociadas al diseño institucional de políticas, y nos señala los fracasos de las políticas como uno de los peligros de no aplicar adecuadamente las correcciones necesarias desde el punto de vista económico.

Justman y Teubal (1991), coincidiendo con Bianchi, destacan que los cambios estructurales son una condición necesaria para el crecimiento y, por lo tanto, la incapacidad de generarlos puede bloquear el posterior desarrollo. Asimismo, concuerdan con Lall en 
CUADRO 2

La intervención para favorecer el desarrollo industrial y tecnológico (DIT)

(Planteamiento de Lall)

Factores determinantes del desarrollo industrial y tecnológico (DIT)

\section{Incentivos:}

Políticas macroeconómicas

Competencia externa

Competencia interna

Habilidades:

Del trabajador y supervisor Técnicas

De ingeniería de producción De diseño y desarrollo

Científicas y de investigación básica

Administrativas, organizacionales y de comercialización

Información y apoyo técnico:

Conocimiento de la necesidad de esfuerzos para promover el DIT Conocimiento del tipo de esfuerzos para promover el DIT Acceso a información de otras firmas, instituciones, universidades, etc.

Estándares, metrología, instalaciones de testeo

Servicios de extensión técnica Implementación de contratos tecnológicos

Servicios de información sobre fuentes técnicas y tendencias Apoyo a la investigación básica Acceso a información

tecnológica mundial

Financiamiento para el DIT:

Disponibilidad de financiamiento a tasas apropiadas y en cantidad suficiente para la investigación y desarrollo (I+D), o la comercialización de innovaciones Financiamiento para innovadores con participación igualitaria Financiamiento especial para las PYME

\section{Políticas tecnológicas:}

Importación de tecnología, inversión extranjera directa, promoción de I+D local, otras intervenciones para fortalecer el DIT
Fallas de mercado

Políticas correctivas
No es aplicable

La exposición completa a la competencia conduce a una inversión insuficiente en DIT debido a externalidades, aprendizaje impredecible, falta de comprensión del proceso de DIT, complementariedades de inversión, asimetría de información, aversión al riesgo.

Poder de mercado, economías de escala y variedad, complementariedades, necesidad de gran tamaño (para ingresar a los mercados mundiales y lograr capacitación e I+D avanzados).

Las inversiones en educación formal padecen de indivisibilidad, mercados ausentes (escasez de oferta de docentes e instalaciones), riesgo, previsión imperfecta, falta de información. El control de calidad y el contenido curricular tienen brechas de información.

Las inversiones de las empresas en capacitación tienen externalidades (inapropiabilidad), se desconocen los beneficios de la capacitación, hay aversión al riesgo y fallas del mercado de capitales.

Asimetrías de información y mercados de información fragmentados (sobre fuentes de tecnología); demoras en el "aprendiendo a aprender"; indivisibilidad de las instalaciones de infraestructura; características de bien público de alguna información (externalidades e inapropiabilidad); asimetría de habilidades; aversión al riesgo; ausencia de intermediación tecnológica.

Insuficiente desarrollo de relaciones entre firmas, provocando una escasa difusión de la tecnología. Inadecuados esfuerzos cooperativos de las empresas para cumplir con estándares y obtener calidad.

Ausencia de lazos con las actividades de investigación en el exterior.

Fallas del mercado de capitales debido a información ausente o asimétrica, selección contraria, riesgo moral, costos de evaluación o ejecución en créditos para DIT; aversión al riesgo o políticas muy conservadoras de los intermediarios financieros.

Falta de habilidades relevantes en la intermediación financiera.

Inversión insuficiente en I+D local (debido a los factores precitados).

La transferencia de tecnología enfrenta las imperfecciones del mercado internacional de tecnología, proveedores monopolistas u oligopolistas, información asimétrica.

Absorción de tecnología importada limitada por las capacidades

locales, junto con otras fallas precitadas que impiden el DIT.
Protección a la industria incipiente (muy selectiva, vigilada, limitada en duración, con salvaguardias, integrada con el desarrollo institucional y de habilidades).

Liberalización en etapas, tomando en cuenta los costos de reaprendizaje.

Asegurar la competencia, regular los monopolios, pero crear complementariamente grandes firmas donde sean necesarias para explotar economías de escala y comercialización.

Apoyo gubernamental a la educación escolar y superior y a la capacitación especial.

Evaluación de calidad y contenidos educativos. Selectividad en la creación de habilidades de nivel superior, insertadas en la estrategia industrial.

Información, incentivos y subsidios para la capacitación en la empresa. Apoyo a la capacitación en el exterior, contratación de capacitadores del exterior.

Información y persuasión sobre la necesidad de actividad técnica. Fortalecimiento de los derechos de propiedad intelectual.

Provisión de servicios de infraestructura; establecimiento de instituciones de I+D para industrias seleccionadas (asegurando las interrelaciones con las empresas)

Servicios de extensión técnica para pequeñas empresas. Servicios de informaciones sobre fuentes de tecnología.

Apoyo a actividades de $\mathrm{I}+\mathrm{D}$ cooperativas en las industrias. Apoyo a actividades de I+D estratégicas. Estímulo a la subcontratación y a la compra de lo local.

Articulación con la I+D extranjera.

Creación de capacidades de financiamiento tecnológico en bancos, con capacitación, subsidios (sólo para comenzar); provisión de financiamiento especial para esfuerzos de DIT que enlacen con instituciones de $\mathrm{I}+\mathrm{D}$; instrumentos financieros para las PYME; capital de riesgo y otros esquemas para proveer instrumentos especiales para compartir riesgos.

Focalización de sectores con potencial tecnológico excepcional.

Incentivos fiscales y de otro tipo para I+D; compra de productos con innovaciones locales; servicio de información sobre fuentes de tecnología, control selectivo de la I+D y negociación para asegurar el desarrollo local del conocimiento técnico. Apoyo selectivo a proyectos de I+D con grandes beneficios y externalidades positivas potenciales.

Fuente: Lall (1993), traducción libre. 
atribuir importancia fundamental a las capacidades y habilidades específicas, y en considerar necesaria una masa crítica de esfuerzos para su aplicación. La combinación de estos dos factores da lugar a una infraestructura de habilidades específicas, en tanto que su inexistencia propicia una asignación de recursos por el mercado que posiblemente sea ineficiente. Esta infraestructura tal vez obligue a decidir entre senderos de desarrollo optativos, que pueden excluirse mutuamente si los recursos son limitados y la masa crítica requerida por uno y otro es relativamente grande. No hay razones para que dicha elección sea eficiente si se hace en forma descentralizada. Tal vez se necesita un esfuerzo coordinado entre diferentes agentes de la economía para seguir el sendero más deseable.

Este enfoque estructuralista implica que la capacidad para generar un cambio estructural "impulsado por la tecnología" es en sí misma una fuente de ventajas comparadas, y pone de relieve la importancia de la acumulación tanto de capital físico como de recursos intangibles. Además, sugiere que existe un nuevo y más complejo rol para el gobierno en la búsqueda del crecimiento industrial, que proviene de la posibilidad de generar ventajas comparativas a través de la promoción del cambio estructural. El cambio estructural, aunque es difícil, puede acelerar el crecimiento económico una vez que se materializa. Esta aceleración se asocia con una "reasignación violenta" de los recursos que acompaña al cambio estructural.

Para el enfoque estructuralista, la generación de ventajas comparativas es un proceso complejo en el cual la acumulación de capital físico interactúa con la acumulación de habilidades específicas y el desarrollo de elementos específicos de la infraestructura tecnológica. La especificidad conduce a temas de política que van más allá de la tasa de ahorro óptima o de la tasa de crecimiento óptima de cualquier variable agregada: el de identificar los cambios estructurales deseables para la economía, y el de definir qué tipo de infraestructura (incluidas las capacidades) debe desarrollarse para inducir tales cambios. Estos temas son estratégicos y de largo plazo por naturaleza, e implican decidirse por uno de los tipos de senderos de desarrollo, que son relativamente indivisibles. Las decisiones de inversión consiguientes son prácticamente irreversibles y afectan a un amplio espectro de agentes económicos presentes y futuros.

Los autores estructuralistas señalan que las fallas de mercado son características del desarrollo, y que se dan particularmente en los "nodos" de cambio estructural, por lo que no pueden ser consideradas como fenómenos aislados o excepcionales. En esos nodos el cambio estructural es factible; sin embargo, la economía puede fallar al implementarlo. Para que tenga lugar, es necesario efectuar una reasignación violenta de recursos ("destrucción creativa"). La coordinación, por lo tanto, es esencial para asegurar que la reasignación deseada tenga lugar y para que no conduzca a trastornos sociales y políticos excesivos. En los nodos de cambio estructural puede ser necesaria una masa crítica de más de uno de los recursos (por ejemplo, habilidades e inversión de capital). Sin un aumento de la inversión en capital físico, podría no ser beneficioso adquirir habilidades avanzadas, mientras que sin una masa crítica de mano de obra capacitada, la rentabilidad del capital invertido podría ser inadecuada. Las indivisibilidades sugieren que el mercado no siempre coordinará automáticamente en forma óptima. Este obstáculo no es un problema sólo en las primeras fases del desarrollo, sino que surge en todos los nodos de cambio estructural que requieren una acumulación concertada de masas críticas de recursos específicos. La formación de este tipo de infraestructura tecnológica es "estratégica", porque las configuraciones particulares pueden determinar el conjunto de industrias en las cuales se están generando futuras ventajas comparativas. El problema que enfrenta la economía es el de elegir programas de inversión indivisibles, cada uno de los cuales conduce a un sendero de crecimiento distinto y está asociado a economías de escala estáticas y dinámicas. No hay razones para que el mercado elija la alternativa más apropiada. Pero esto no significa que el gobierno tenga la capacidad de hacerlo. Sin embargo, está cada vez más claro que el gobierno debe desempeñar un papel en la coordinación del cambio. En primer lugar, puede proveer un foro para el debate entre las partes interesadas de la economía, y posiblemente un medio de reforzar los compromisos mutuos para embarcarse en un sendero de cambio. En segundo lugar, puede ser un enlace entre el análisis profesional y las fuerzas políticas, que es necesario para resolver los problemas de distribución y equidad que invariablemente acompañan al cambio estructural.

El debate sobre las fallas del gobierno ocupa un lugar central en las publicaciones sobre política industrial, pues tales fallas determinarán en gran medida el resultado de las políticas que se adopten. Shapiro y Taylor (1990) han efectuado una revisión de los argumentos esgrimidos, en la que consideran las dificultades existentes, pero a la vez ponen de relieve los casos en que ha sido posible efectuar intervenciones en la dirección señalada. 


\section{V}

\section{La interacción macroeconómica y microeconómica}

Cuando se examinan las políticas que promueven el desarrollo, los problemas de coordinación macroeconómica ocupan un lugar secundario, sólo a modo de contexto de políticas más específicas. Sin embargo, la interacción de las configuraciones macroeconómica y microeconómica condiciona en gran medida la potencialidad de crecimiento de una economía.

En el análisis de los problemas de coordinación a nivel macro, el aporte de Leijonhufvud (1981) es fundamental para intentar comprender algunos rasgos que presenta el comportamiento de las economías en desarrollo en situaciones de desequilibrio. Su visión puede resumirse así: el sistema económico se comportará de manera diferente según qué tipo de desplazamiento del sendero de "coordinación completa"3 ocurra. Si el desplazamiento es moderado y el sistema se ubica dentro de un rango que Leijonhufvud denomina "corredor", 4 los mecanismos homeostáticos entrarán en funcionamiento y corregirán las tendencias. Fuera del corredor, estos mecanismos son más débiles y el sistema está crecientemente sujeto a "fallas de demanda efectiva". ${ }^{5}$ Dentro del corredor las repercusiones multiplicadoras son débiles y están dominadas por los ajustes de mercado neoclásicos; fuera del corredor, ellas son suficientemente fuertes como para amplificarse de manera endógena como efecto de las perturbaciones (shocks) sobre el estado anterior. Por lo tanto, los multiplicadores aumentarán con la distancia que exista en relación al sendero ideal.

La macroeconomía convencional considera que el desplazamiento del sendero lleva a las economías a ubicarse dentro del corredor. Por lo tanto, el desequi-

\footnotetext{
${ }^{3}$ La "coordinación completa" implica que los mercados existentes se limpian; se refiere a aquel estado en que todos los excesos de demanda y de oferta son eliminados. No implica "asignación eficiente".

${ }^{4}$ La amplitud del corredor es variable y está determinada principalmente por el acervo de activos líquidos que mantienen los agentes económicos. Estos acervos actúan como amortiguadores en el momento en que los shocks impactan sobre la economía. Cuando éstos son de gran magnitud y no han sido anticipados, los amortiguadores quedan exhaustos, agudizándose los problemas de coordinación.

${ }^{5}$ La falla de demanda efectiva es la falla de los mercados para transmitir mensajes sobre las transacciones deseadas, desde un lugar a otro.
}

librio es temporal y el problema de política estará dado por la búsqueda de instrumentos que permitan disminuir el período en que las economías se encuentran fuera de equilibrio. Pero, como señalan Fanelli y Frenkel (1995), este enfoque no es el adecuado cuando se analiza el problema macroeconómico en las economías latinoamericanas, debido a la magnitud, la duración temporal y la recurrencia de sus desequilibrios a nivel macro. Estas economías tienden a ubicarse sistemáticamente fuera del corredor de Leijonhufvud, donde los desequilibrios se potencian.

Hay un rasgo que sintetiza la diversidad de factores que contribuyen a determinar la propensión de una economía a generar fallas de coordinación: el grado de volatilidad e impredictibilidad estocástica en la evolución de las variables fundamentales. Cuanto mayor sea la volatilidad, mayor será la dificultad de anticipar su evolución y la propensión de la economía a generar desequilibrios macroeconómicos. Una economía con tales características causará conductas a nivel microeconómico que estarán ausentes cuando esos elementos no se dan y que incluso pueden orientarse en sentido contrario al que cabría esperar si el fenómeno fuera esporádico. Una cosa es pasar por una etapa de desequilibrio y otra vivir en una economía propensa a generarlo en forma sistemática. En esta última situación la influencia de lo macro sobre la estructura micro será mucho más permanente y visible. Hay rasgos de la estructura económica que no pueden explicarse sólo en términos micro y sin hacer referencia al contexto macro en que se produjeron. Las mutaciones que se observan están de una u otra manera relacionadas con el hecho de que en una economía de alta incertidumbre macroeconómica la flexibilidad para cambiar decisiones del pasado tiene un premio económico. La "preferencia extrema por la flexibilidad" tiene consecuencias fundamentales sobre la asignación de recursos reales, sobre la morfología financiera y, a través de sus efectos en la inversión y la capacidad de innovación, sobre el crecimiento.

Al mismo tiempo que distintas configuraciones macroeconómicas determinan diferentes comportamientos y estructuras a nivel micro, las características 
estructurales de cada economía (los factores micro) son relevantes en la determinación del grado de inestabilidad macroeconómica. Por un lado, cuanto mayor sea el número e importancia de las fallas de mercado y menor el grado de desarrollo de las instituciones relacionadas con la actividad económica, mayor será la debilidad - $\mathrm{o}$ ausencia - de mecanismos de mercado que amortigüen el desequilibrio, y mayor por lo tanto la tendencia de las economías a generar desequilibrios y seguir senderos de ajuste dinámico que tiendan a reproducir o amplificar los desequilibrios en lugar de corregirlos. Esto se debe a que la capacidad de auto- rregulación de la economía depende del grado de desarrollo de los mercados y las instituciones, que son los encargados de administrar la incertidumbre inherente a todas las actividades económicas. Por otro lado, cuanto menor sea la diversificación y sofisticación productivas, menor será la capacidad de reasignar rápidamente los recursos a nuevas actividades ante la ocurrencia de perturbaciones permanentes $\mathrm{y}$, por lo tanto, mayor el período durante el cual la economía funcionará en desequilibrio. Ambos hechos son característicos de las economías en desarrollo latinoamericanas.

\section{VI}

\section{El debate en el Banco Mundial}

Durante los años ochenta, la posición adoptada por el Banco Mundial sobre el papel de las intervenciones gubernamentales en la economía, y particularmente en el desarrollo industrial, estaba claramente expresada en el conjunto de políticas basadas en lo que Williamson (1990) llamó el Consenso de Washington. Según este enfoque, se debían adoptar las medidas indicadas por el modelo de crecimiento neoclásico, según el cual las fuerzas de mercado por sí solas permitirían una óptima asignación de los recursos, y dejar de lado el papel fundamental que los países menos desarrollados asignaban a las intervenciones selectivas del Estado como "motor de desarrollo". De este modo, para el Consenso de Washington la política industrial estaba definitivamente excluida como forma de mejorar cualquier situación económica. Los criterios de política se articulaban a través de la apertura económica, la desregulación y el proceso de privatizaciones que estaban en la base de las reformas estructurales propuestas por el Banco Mundial y que eran requisitos para la obtención de créditos.

Sin embargo, la propia operatoria del Banco Mundial llevó a que poco a poco surgieran distintos puntos de vista dentro de la institución acerca del papel del Estado en el desarrollo económico, e hizo que la visión neoclásica pura que dominaba las prescripciones de la institución se viera cuestionada tanto en su sustento teórico como en el empírico. Así, dentro del propio Banco Mundial aparecieron informes de funcionarios que reexaminaban los argumentos del Banco; al mismo tiempo, se modificaron las condiciones que debían cumplir los países para obtener préstamos y ser evaluados positivamente por la institución. Uno de los primeros desafíos a la postura del Banco provino de los documentos elaborados por su Departamento de Industria y Energía .

Ejemplo de lo dicho es un estudio encargado a dicho departamento y realizado por Atiyas, Dutz y Frischtak (1992), cuyo objetivo era establecer un marco conceptual para los problemas de la reconversión industrial. El marco analítico elaborado en dicho informe se ofrece como herramienta para guiar las acciones gubernamentales con el fin de crear un medio que estimule la eficiente reconversión de la industria. Identifica los principales obstáculos para la adopción de decisiones de reconversión convenientes y los agrupa en tres grandes categorías: disciplina, movilidad/versatilidad y recursos. Los obstáculos a la disciplina son aquellos que protegen a las empresas de las fuerzas de la competencia, prolongan su supervivencia y permiten que los gerentes pospongan las decisiones de reconversión. Los obstáculos que restringen la movilidad reducen la capacidad de las empresas para reasignar los factores en respuesta a un entorno cambiante. Sin embargo, se ha visto que la disciplina y la movilidad no bastan para provocar reconversiones relativamente eficientes cuando los recursos (experiencia, información y financiación) no se encuentran disponibles. Para cada grupo de obstáculos el informe clasifica las acciones gubernamentales necesarias para eliminar distorsiones en las políticas aplicadas, presentar reglas y mecanismos que compensen los fracasos del mercado, y crear instituciones para aplicar dichas reglas.

En otro informe, Frischtak (1993) sostiene que la flexibilidad laboral y la capacidad de reubicar capita- 
les con rapidez son los requisitos más importantes en las fases iniciales o defensivas de la reconversión. Para lograr flexibilidad laboral es necesario eliminar las regulaciones laborales restrictivas, introducir compensaciones adecuadas por desempleo y apoyar las actividades de reubicación y readiestramiento de la mano de obra. Para reubicar capitales prontamente, la restricción que más pesa suele ser la escasez de crédito, por lo que son útiles los subsidios de salida de la actividad financiados con impuestos a las empresas que permanezcan o los subsidios por cambio de actividad que faciliten a las empresas el abandono de las líneas de producción menos rentables. Si la reconversión resulta exitosa, suele aumentar la productividad y la rentabilidad de las firmas. Sin embargo, el mantenimiento de la posición lograda demanda bastante más esfuerzo empresario y la aplicación de diversas medidas que conduzcan a una reconversión satisfactoria. Esto incluye la adopción de una postura agresiva en el campo tecnológico, la obtención de financiamiento para las inversiones y la innovación y, fundamentalmente, una nueva cultura organizacional que ponga el acento en los beneficios de largo plazo de dichas inversiones e innovaciones.

El desempeño de varios países del este asiático durante el último cuarto de siglo atrapó la atención del mundo entero. Este conjunto de naciones alcanzó tasas de crecimiento elevadas y sostenidas por largo tiempo, acompañadas por una mejora apreciable en el ingreso de la población y en la distribución de este ingreso. En los años ochenta, el éxito alcanzado por estas naciones fue considerado una confirmación de las prescripciones de raíz neoclásica que preconizaba el Banco Mundial, contraponiéndolo con la experiencia sufrida por aquellas naciones que emprendieron el camino de la sustitución de importaciones a través de la protección del mercado interno y de una activa intervención gubernamental. Sin embargo, las diferencias percibidas entre las políticas aplicadas por los países del este asiático y las políticas prescritas por el Banco Mundial llevaron a que la Delegación del Japón ante el Banco sugiriera realizar un estudio para reexaminar el papel que le había cabido al gobierno en el desarrollo económico, y particularmente industrial, de la región (véase OECF, 1991).

El estudio sugerido se efectuó (Banco Mundial, 1993). ${ }^{6}$ Entre sus conclusiones más importantes está la

\footnotetext{
${ }^{6}$ Así surgió el estudio The East Asian Miracle: Economic Growth and Public Policy, realizado por el Banco Mundial en 1993 y dirigido por J. Page, que tuvo por objeto estudiar el proceso de desa-
} rrollo de las naciones del este asiático. que señala que en las economías del este asiático, en una forma o en otra, el gobierno intervino — sistemáticamente y a través de múltiples canales - para promover el desarrollo. Clasifica las políticas aplicadas en dos grandes grupos: equilibrios macroeconómicos básicos e intervenciones selectivas. De los primeros, entre los más importantes están la estabilidad macroeconómica, grandes inversiones en capital humano, sistemas financieros estables y seguros, distorsiones de precios limitadas y apertura a la tecnología extranjera. Las intervenciones selectivas incluyen represión financiera moderada (manteniendo tasas de interés positivas pero bajas), crédito dirigido, promoción industrial selectiva y políticas comerciales de empuje exportador.

El trabajo se centra en una clase de problemas económicos, las fallas de coordinación, que pueden conducir a fallas de mercado, especialmente en las primeras etapas del desarrollo, e interpreta algunas de las políticas intervencionistas aplicadas por los países del este asiático como respuestas a estos problemas de coordinación. Tales políticas hacen hincapié en conductas cooperativas entre las firmas privadas y en estándares de éxito transparentes, basados en el desempeño.

Algunos de los países del este asiático considerados en este estudio fueron un paso más allá y crearon certámenes económicos (contests) que combinan la competencia con los beneficios de la cooperación, tanto entre firmas como entre el gobierno y el sector privado. La característica clave de cada certamen es que el gobierno distribuye recompensas (asignaciones) según el desempeño de las empresas, que es verificado por el gobierno y por las firmas que compiten. Tales certámenes necesitan jueces competentes e imparciales; es decir, instituciones fuertes. Por lo tanto, un servicio civil de alta calidad capaz de verificar desempeños e inmune a interferencias políticas, es un elemento esencial de la asignación basada en certámenes como los descritos. Por supuesto que un servicio civil de alta calidad también refuerza las habilidades del gobierno para diseñar e implementar políticas que no se basan en certámenes.

El rápido crecimiento de los países del este asiático tuvo dos elementos complementarios. El primero - esencial— fue haber alcanzado equilibrios macroeconómicos básicos. La administración de la macroeconomía fue inusualmente buena y el desempeño macroeconómico inusualmente estable, suministrando así el marco para las inversiones privadas. Las políticas encaminadas a incrementar la integridad del sistema bancario y hacerlo más accesible a los ahorristas no tradicionales aumentaron los niveles de ahorro fi- 
nanciero. Las políticas educativas, que se focalizaron en la educación primaria y secundaria, generaron rápidos incrementos en las habilidades de la fuerza de trabajo. Las políticas agrícolas forzaron el cambio en la productividad y no cargaron excesivamente de impuestos a la economía rural. Por último, todos los países mantuvieron las distorsiones de precios dentro de límites razonables y se abrieron a las ideas y la tecnología del exterior. El segundo elemento fueron las políticas intervencionistas cautelosas. Los requisitos previos para lograr el éxito, sin embargo, eran tan rigurosos, que las políticas formuladas en otros países en desarrollo que buscan seguir senderos similares a menudo han fracasado. Al respecto, el estudio que comentamos realza la importancia que tuvo la base institucional para el desempeño alcanzado.

Las conclusiones a las que llegó el estudio del Banco Mundial sobre las causas del milagro del este asiático dieron inicio a un nuevo debate que aún hoy continúa y que se expresó recientemente en una sección especial dedicada al tema en la publicación World Development (1994). Allí aparece, editado por A. Amsdem, un conjunto de informes que resumen algunas críticas que se le han hecho .

El primero de esos informes pertenece a la propia A. Amsden, quien señala que al centrarse en los equilibrios macroeconómicos básicos, el trabajo del Banco Mundial sugiere que el crecimiento económico es un proceso bastante sencillo. Esto se contradice con todos los nuevos modelos de crecimiento, los cuales ponen de relieve que, debido a la imperfecta información, las rentabilidades crecientes, los equilibrios múltiples, la dependencia del sendero elegido, los mecanismos que se autorrefuerzan, y otras propiedades dinámicas, el proceso de crecimiento no tiene una explicación única. El desacuerdo surge del error del Banco Mundial de creer que es posible que las variables macroeconómicas básicas (inversión, educación, exportaciones) se desentiendan de sus fundamentos microeconómicos o instituciones que los sostienen. Cuando tales variables y fundamentos están integrados, y las variables macroeconómicas básicas se insertan en el contexto en que se formulan e implementan las políticas, el crecimiento se hace complejo, como lo sugieren los nuevos modelos formales. El intento del Banco Mundial de atribuír la mayor parte del desarrollo del este asiático al "fundamentalismo de mercado" se vuelve engañoso. Por ejemplo, si el este asiático ha tenido altas tasas de ahorro e inversión, éstas surgen sólo en conjunción con una particular estructura de empresa y de sistema financiero (todos los bancos en la República de Corea y de la provincia de Taiwán eran de propiedad pública).

Lall, por su parte, creee que el estudio del Banco se inscribe en la visión facilitadora del funcionamiento del mercado elaborada en el Informe sobre el desarrollo mundial (Banco Mundial, 1994). Luego de formular un conjunto de críticas al trabajo a partir de su visión "estructuralista" vinculada a las capacidades tecnológicas (argumentos que ya desarrollamos más atrás), indica que el éxito de las políticas industriales de los países del este asiático debe ser juzgado en función de las diferentes estrategias que siguieron. Lo que un gobierno considera falla de mercado depende de sus objetivos: lo que puede haberse mirado como un progreso satisfactorio en Hong Kong, puede ser visto como inadecuado (y por lo tanto propenso a fallas de mercado) en la República de Corea. La valoración de las fallas de mercado requiere un examen del aprendizaje tecnológico a nivel micro. Entre los países estudiados hubo cruciales diferencias de objetivos tecnológicos. Las estrategias consiguientes conducen a sustanciales diferencias en materia de estructuras industriales, exportaciones en que se especializan, grados de contenido local, capacidades tecnológicas endógenas, dependencia de modos diferentes de transferencia tecnológica e involucramiento - continuo o no- del gobierno. Los efectos de las políticas industriales no pueden ser evaluados sin referencia a las estrategias seguidas. Para juzgar adecuadamente tales políticas habría que examinar, entre otras cosas, la complejidad de las actividades industriales dentro y a través de las industrias, la composición y sofisticación tecnológica de las exportaciones de manufacturas, la extensión de la integración local y la profundización tecnológica local. Estas fueron las facetas de la industrialización de los países del este asiático en las cuales sus estrategias se diferenciaron; sus fallas de mercado fueron identificadas y a ellas se dirigieron las intervenciones. Los países que más avanzaron fueron justamente los que aplicaron fuertes políticas de intervención selectiva, como Japón y la República de Corea, y que exhibieron mayores distorsiones en los precios relativos, como muestran los datos del Banco Mundial.

En los últimos tiempos surgieron nuevos síntomas de cambio en el pensamiento económico. En septiembre de 1996 se realizó en Washington la Conferencia sobre el Pensamiento y la Práctica del Desarrollo, organizada por el Banco Interamericano de Desarrollo (BID). En ese marco, John Williamson presentó su trabajo "The Washington Consensus revisited". Este nuevo estudio de Williamson no es una revisión oficial del 
consenso original, sino el resultado de un cambio en el escenario de la política económica internacional. Temas que antes estaban vedados aparecen ahora en el centro de la controversia. Entre las nuevas ideas que expresa Williamson están: el aumento del ahorro, preservando la disciplina fiscal (que por sí sola es insuficiente); la reorientación del gasto público hacia un gasto social bien focalizado; una reforma tributaria que incorpore las externalidades del medio ambiente; la supervisión bancaria por parte del Estado; una tasa de cambio competitiva; el uso del poder de negociación de los bloques económicos en la liberalización comercial; el fomento de la competencia en los mercados; derechos de propiedad bien definidos al alcance de todos (reducción de la desigualdad en la distribución de las tierras); la creación de instituciones estatales o mixtas para realizar políticas sociales y de promoción, y el mejoramiento de la educación, aumentando el gasto y redirigiéndolo hacia la enseñanza primaria y secundaria. Finalmente, en un reciente artículo de Joseph Stiglitz (1996) se reseña la reevaluación de la experiencia de los países del este asiático, haciendo hincapié en el papel cumplido por las intervenciones gubernamentales.

\section{VII}

\section{El enfoque sistémico de la CEPAL}

Un reciente documento de la CEPAL (1995) analiza los factores exógenos del escenario internacional y se centra en la exploración de políticas interrelacionadas: i) la política macroeconómica, en especial los flujos financieros, ii) la política comercial y iii) la política microeconómica y mesoeconómica. En el marco de un enfoque sistémico, intenta agrupar en forma coherente los distintos planteamientos, señalando las dificultades de generalizar en un contexto regional que presenta una enorme diversidad de situaciones.

Las políticas mesoeconómicas y microeconómicas de desarrollo productivo planteadas por la CEPAL parten de la base de que es necesario contar con políticas macroeconómicas, institucionales y comerciales adecuadas, e indagar en las causas de la diferencia (brecha) de productividad entre los países latinoamericanos y los países desarrollados y en las recomendaciones de política que permitan superarla. El gráfico 1 muestra el planteamiento actual de la CEPAL, señalan- do las implicaciones de política, los obstáculos para superar la diferencia de productividad y la justificación teórica y empírica de una política activa de desarrollo productivo.

Asimismo, Ramos (1996) plantea que, a medida que las economías de América Latina se han ido estabilizando, ha resurgido en la región el interés por diseñar estrategias de desarrollo a más largo plazo, que faciliten el paso de una trayectoria de lento crecimiento a otra de crecimiento mucho más rápido, como la lograda por los países de desarrollo tardío exitosos del este asiático. Su análisis subraya dos aspectos centrales: primero, el proceso de apertura y reestructuración en que se encuentran los países latinoamericanos desde mediados de los años ochenta y, segundo, la enorme diferencia de productividad que existe entre las empresas de la región y las que utilizan las mejores prácticas internacionales en el mundo desarrollado.

\section{VIII}

\section{Reflexiones finales}

Toda nueva propuesta industrial requiere una adecuada evaluación de los aspectos positivos de aprendizaje que se generaron en el pasado y de los problemas asociados a los errores que se cometieron. Uno de los primeros grandes desafíos es el de generar condiciones para aprovechar lo bueno de experiencias que han involucrado considerables acervos tecnológicos, económicos y de calificación de los recursos humanos, pero, a la vez, es indispensable superar las insuficiencias y limitaciones de esas experiencias para avanzar hacia la adquisición de ventajas comparativas dinámicas. 


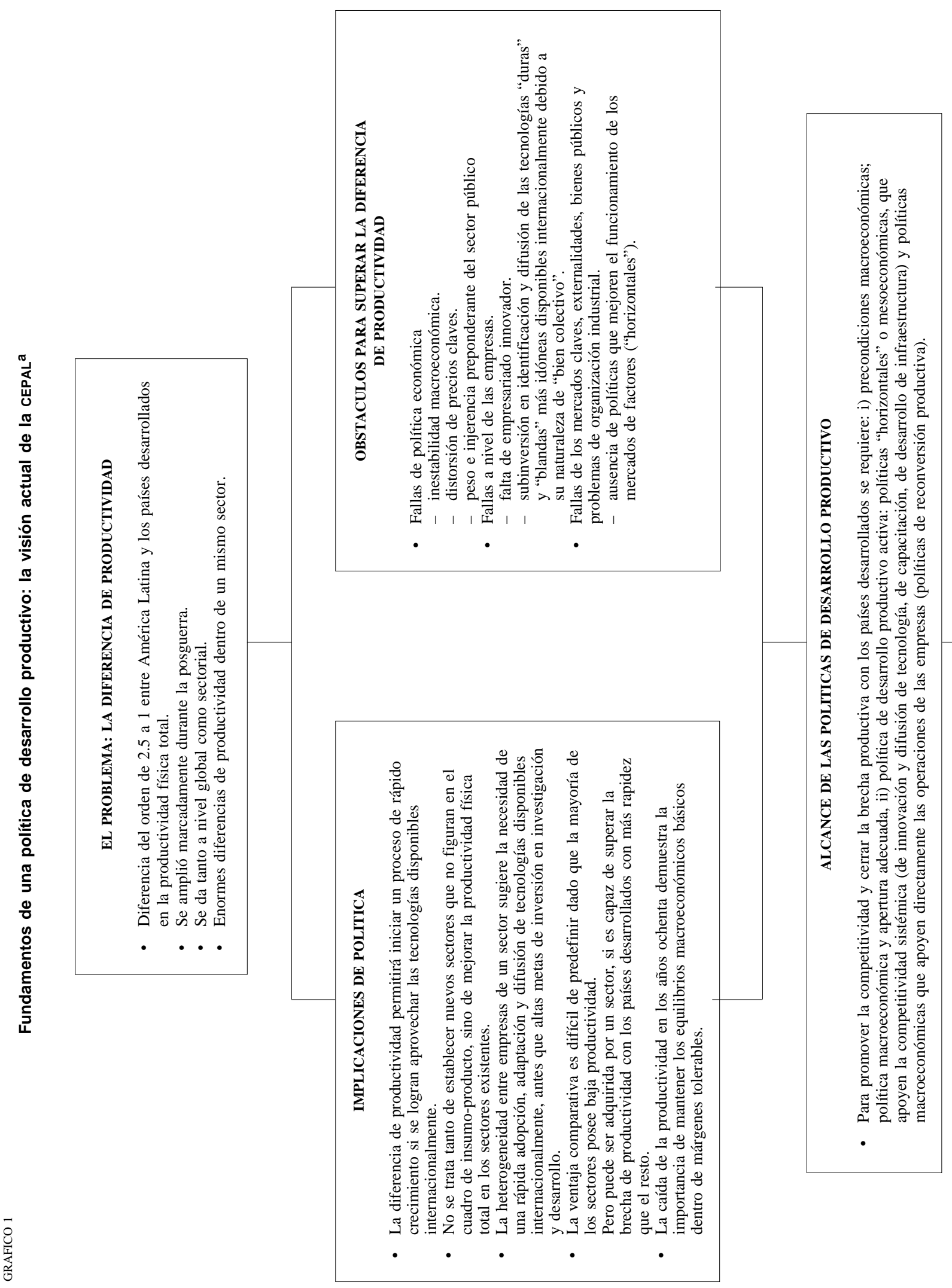



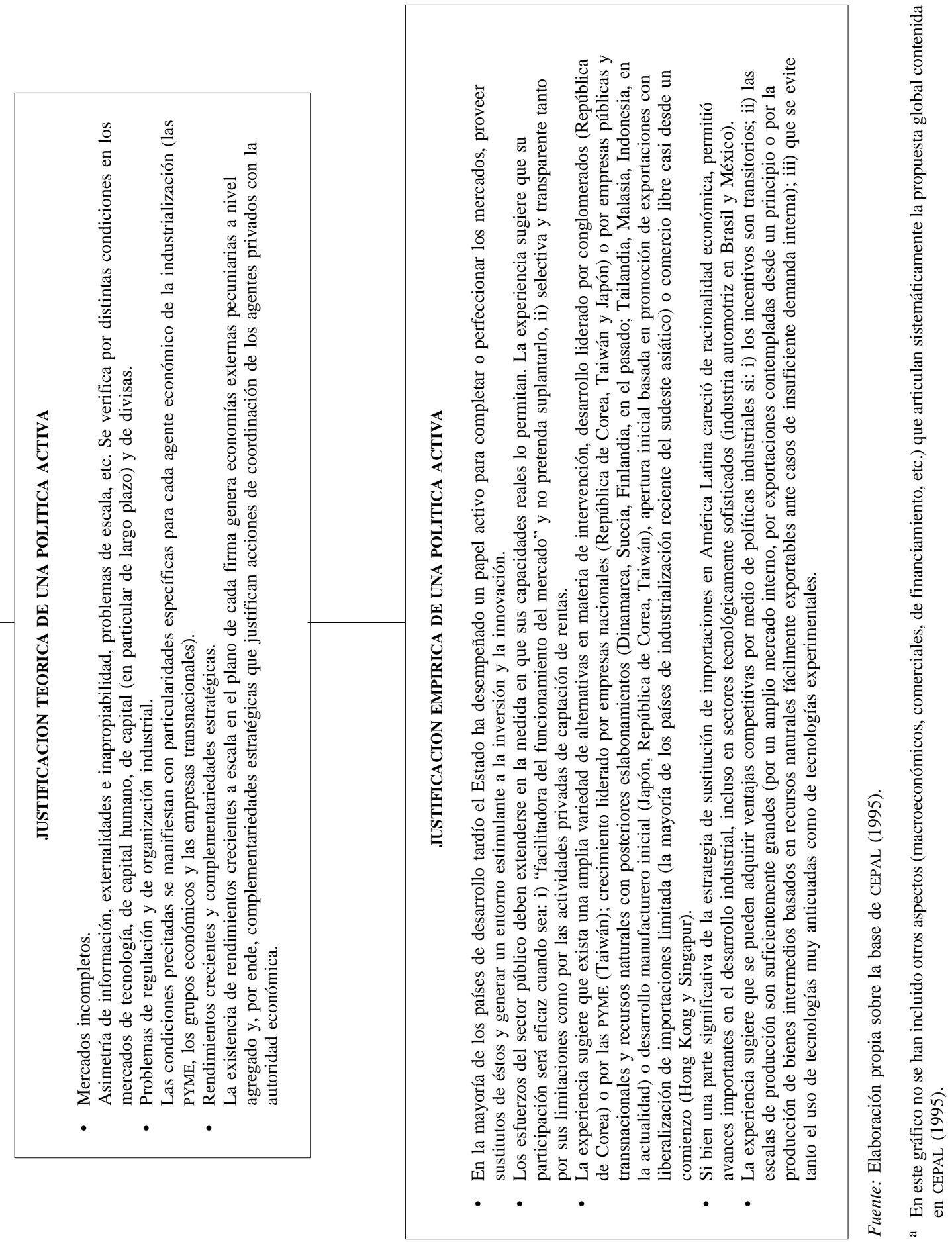
La posibilidad de alcanzar niveles cada vez mayores de competitividad y de mantenerlos en el largo plazo no puede circunscribirse a la acción de un agente económico individual. La experiencia internacional muestra que los casos exitosos se deben a un conjunto de variables, y que es el funcionamiento global del sistema el que permite lograr una base sólida para el desarrollo de la competitividad. De esta forma, la noción sistémica de competitividad reemplaza a los esfuerzos individuales que, si bien son condición necesaria para lograr este objetivo, deben estar acompañados necesariamente por innumerables aspectos que conforman el entorno de las firmas (desde la infraestructura física, el aparato científico tecnológico, la red de proveedores y subcontratistas y los sistemas de distribución y comercialización, hasta los valores culturales, las instituciones y el marco jurídico). La competitividad sostenible en el largo plazo se logra con esfuerzos sistemáticos por adquirir ventajas comparativas y consolidar un "proceso endógeno continuo" que abarque los aspectos señalados, definiendo simultáneamente las responsabilidades del empresario dentro de su planta industrial y las condiciones que conforman su entorno, que incluye tanto a otros agentes privados como al sector público.

Esta noción sistémica de la competitividad es pertinente para cada uno de los mercados en que es considerada. Por lo tanto debe aplicarse tanto a los mercados de exportación como respecto a las importaciones potenciales. La experiencia latinoamericana ha demostrado que varias producciones han podido expandirse, pero lo han hecho sobre bases de sustentación claramente endebles. Estas formas de competitividad fueron calificadas de espurias (Fajnzylber, 1990) porque no avanzaban en la adquisición de ventajas comparativas y estaban cimentadas en uno o varios de los siguientes factores: bajos salarios, procesamiento de recursos naturales sin preservar el medio ambiente; tipos de cambio elevados, recesión en el mercado local, sobreprotección contra las importaciones para sectores ineficientes, elevados subsidios a las exportaciones, etc. Estas formas viciosas de competencia derivaban en frágiles éxitos individuales de las firmas, pero eran incompatibles con beneficios de carácter social. Tales avances no podían sostenerse en el largo plazo y entraban en crisis, tanto por el desempeño de la empresa como por los elevados costos sociales involucrados.

El progreso industrial y la consecución de los objetivos estratégicos perseguidos dependerán de la capacidad y creatividad gubernamental para diseñar y llevar a cabo las acciones que mejor se adecuen —en tiempo, intensidad y cobertura - a los patrones de comportamiento de los distintos agentes económicos. El diseño, formulación y despliegue de políticas gubernamentales activas, explícitas y transparentes, así como su necesaria inscripción en una concepción estratégica de largo plazo, demandan armonía y coordinación entre los organismos públicos, a la vez que requieren su articulación con las políticas de corto plazo. Por otra parte, surge como condición ineludible la redefinición de la "ingeniería institucional" necesaria. La debilidad e incluso fragilidad técnica de las estructuras estatales obliga a focalizar los esfuerzos en acciones cuya transparencia facilite la necesaria evaluación posterior de sus resultados. En tal sentido, las posibilidades de desarrollar políticas selectivas se ven acotadas y condicionadas por la fragilidad del sector público.

Un marco macroeconómico consistente es condición indispensable para implementar la política industrial, que a su vez debe tener claros algunos criterios básicos. En particular, estas políticas han de ser explícitas, activas, y lo más generales y neutras posibles. Asimismo, es preciso privilegiar las acciones que tengan mayores efectos propulsores y difusores de externalidades positivas en el conjunto de la economía . En este último punto, la consolidación de la infraestructura y el mejoramiento del capital humano son dos de los aspectos más importantes (Ffrench-Davis, 1990; Teubal, 1990).

El planteamiento de una política explícita está asociado necesariamente a una evaluación social ex ante y ex post, a la cuantificación de las transferencias presupuestarias que pudieran estar involucradas (especificando quién las recibe y quién las financia), a una total transparencia, a objetivos nítidamente expresados y cuantificados, así como a una secuencia temporal clara y con elementos de promoción que de preferencia sean decrecientes en el tiempo. Por lo tanto, es preciso contar con un sistema de premios, pero también con uno de castigos si no se alcanzan los objetivos comprometidos.

Estos aspectos tienen vital importancia para lograr los objetivos deseados. Son innumerables las experiencias nacionales de apoyo al proceso de maduración de las industrias incipientes, pero sus resultados han sido poco exitosos. Sin duda los problemas que plantea la selección de los sectores y de las técnicas adecuadas no son menores. Sin embargo, la evaluación de dichas experiencias ha demostrado que uno de los aspectos cruciales está asociado al hecho de que los procesos de aprendizaje no surgen automáticamente con el trans- 
curso del tiempo. Por el contrario, resultan de esfuerzos deliberados y explícitos orientados a generar acervos tecnológicos y a capacitar a los recursos humanos. Así, se debe desarrollar una estrategia tecnológica y productiva asociada a inversiones que se orienten a la generación o adopción de cambios técnicos permanentes, para inducir una maduración que no es automática ni instantánea y que requiere esfuerzos permanentes y deliberados.

Cuando los problemas económicos se suman a la fragilidad institucional, de lo que se trata no es de "retornar al mercado" sino de "construir el mercado"; es decir, de actuar sobre las instituciones de la vida colectiva y proporcionar las capacidades que permitan a la mayoría de los sujetos participar efectivamente en ella. Asimismo, las políticas públicas para el desarrollo industrial deben apuntar no sólo a favorecer cambios en el contexto institucional en el que operan las empresas, sino también a acciones concretas para favorecer la cooperación industrial entre las firmas y permitir así la especialización individual en un contexto de complementariedad y extensión del mercado.

Los regímenes de política industrial ofrecen mecanismos de coordinación que faltan en las economías de mercados libres. Como mecanismo de coordinación, la política industrial puede ser más eficiente allí donde la interdependencia y la especificidad de los activos son importantes. La política industrial debe ayudar a coordinar el cambio económico, a fomentar la experimentación y a preservar la diversidad. En el mundo real, muchos cambios involucran decisiones interdependientes. Al examinar la lógica de la política industrial, cabe separar el papel que desempeña en dos dimensiones distintas: una estática y otra dinámica. En ambos casos la función de la política industrial es la misma: evitar fallas de coordinación.

\section{Bibliografía}

Arrow, K. (1962): Economic welfare and the allocation of resources for innovation, R. Nelson (ed.), The Rate and Direction of Innovative Activity, Princeton, New Jersey, Princeton University Press.

Atiyas, I., M. Dutz y C. Frischtak (1992): Fundamental Issues and Policy Approaches in Industrial Restructuring, Industry series paper, $\mathrm{N}^{\circ} 56$, Washington, D.C., Banco Mundial, Departamento de Industria y Energía.

Banco Mundial (1994): Informe sobre el desarrollo mundial 1991, Washington, D.C.

(1993): The East Asian Miracle: Economic Growth and Public Policy, Nueva York, Oxford University Press.

Bianchi, P. (1994): Industrial strategy in an open economy, P. Bianchi, K. Cowling y R. Sugden (eds.), Europe's Economic Challenge: Analyses of Industrial Strategy and Agenda for the 1990s, Londres, Routledge.

(1993): An industrial strategy for small and medium-sized enterprises in an open economy: An European perspective, Boloña, Italia, Universidad de Boloña, diciembre.

CEPAL (Comisión Económica para América Latina y el Caribe) (1995): América Latina y el Caribe: políticas para mejorar la inserción en la economía mundial, LC/G.1800/Rev.1-P, Santiago de Chile. Publicación de las Naciones Unidas, $\mathrm{N}^{\circ}$ de venta S.95.II.G.6.

Chang, H. (1994): The Political Economy of Industrial Policy, Nueva York, St. Martin's Press.

Fajnzylber, F. (1990): Industrialización en América Latina: de la 'caja negra' al 'casillero vacío', Cuadernos de la CEPAL, $\mathrm{N}^{\circ}$ 60, LC/G.1534/Rev.1-P, Santiago de Chile, CEPAL.

Fanelli, J. y R. Frenkel (1995): Estabilidad y estructura: interacciones en el crecimiento económico, Revista de la CEPAL, $\mathrm{N}^{\circ} 56$, LC/G.1874-P, Santiago de Chile, CEPAL.

Ffrench-Davis, R. (1990): Ventajas comparativas dinámicas: un planteamiento neoestructuralista, CEPAL, Elementos para el diseno de políticas industriales y tecnólogicas en América Lati$n a$, Cuadernos de la CEPAL, $\mathrm{N}^{\circ}$ 63, LC/G.1565-P, Santiago de Chile.
Frischtak, C. (1993): Reconversión industrial defensiva y reconversión industrial positiva, Documento de trabajo, $\mathrm{N}^{\circ} 10$, Buenos Aires, Unión Industrial Argentina (UIA), Instituto para el Desarrollo Industrial, mayo.

Grossman, G. (1990): Promoting new industrial activities: a survey of recent arguments and evidence, OECD Economic Studies, $\mathrm{N}^{\circ} 14$, París, Organización de Cooperación y Desarrollo Económicos (OCDE).

Justman, M. y M. Teubal (1991): A structuralist perspective on the role of technology in economic growth and development, World Development, vol. 19, № 9, Oxford, Reino Unido, Pergamon Press.

Lall, S. (1992a): Technological capabilities and industrialization, World Development, vol. 20, N 2, Oxford, Reino Unido, Pergamon Press.

(1992b): Technological capabilities and the role of government in developing countries, Greek Economic Review, vol. $14, \mathrm{~N}^{\circ} 1$, Atenas.

(1993): Understanding technology development, Development and Change, vol. 24, $\mathrm{N}^{\circ}$ 4, Londres, Institute of Social Studies.

(1994a): The East Asian Miracle study: Does the bell toll for industrial strategy?, World Development, vol. 22, № 4 , Oxford, Reino Unido, Pergamon Press.

(1994b): Industrial Policy: The role of government in promoting industrial and technological development, UNCTAD Review 1994, Ginebra, Conferencia de las Naciones Unidas sobre Comercio y Desarrollo (UNCTAD). Publicación de las Naciones Unidas, $\mathrm{N}^{\circ}$ de venta E.94.II.D.19.

Leijonhufvud, A. (1981): Information and Coordination: Essays in Macroeconomic Theory, Nueva York, Oxford University Press.

Nelson, R. (1989): Capitalism as an engine of progress, Research Policy, vol. 19, Amsterdam, Países Bajos, Elsevier Science Publishers, B. V.

OECF (Fondo de Cooperación Económica a Ultramar) (1991): Discussion papers, $\mathrm{N}^{\circ} 7$, Washington, D.C., Banco Mundial. 
Ramos, J. (1996): Política industrial y competitividad en economías abiertas, Desarrollo productivo, $\mathrm{N}^{\circ} 34$,Santiago de Chile, CEPAL.

Shapiro, H. y L. Taylor (1990): The State and industrial strategy, World Development, vol. 18, $\mathrm{N}^{\circ}$ 6, Oxford, Reino Unido, Pergamon Press.

Stiglitz, J. (1993): The role of the State in financial markets, Banco Mundial, Proceedings of the World Bank Annual Conference on Development Economics. 1993, Washington, D.C.

(1996): Some lessons from the East Asian Miracle, The World Bank Research Observer, vol. 11, N², Washington, D.C., Banco Mundial.
Teubal, M. (1990): Lineamientos para una política de desarrollo industrial y tecnológico. La aplicabilidad del concepto de las distorsiones del mercado, en CEPAL, Elementos para el diseño de políticas industriales y tecnológicas en América Latina, Cuadernos de la CEPAL, $\mathrm{N}^{\circ}$ 63, LC/G.1565-P, Santiago de Chile.

Williamson, J. (1990): What Washington means by policy reform?, Latin American Adjustment: How Much Has Happened?, Washington, D.C., Institute for International Economics (IIE).

World Development (1994): vol. 22, º 4, Oxford, Reino Unido, Pergamon Press. 